\title{
Application of Digital Image Correlation for Comparison of Deformation Response in Fusion and Friction Stir Welds
}

\author{
Kathryn A. Dannemann ${ }^{1} \cdot$ Rory P. Bigger $^{1} \cdot$ Nikki L. Scott $^{1} \cdot$ Carl E. Weiss $^{1}$ • \\ Alexander J. Carpenter ${ }^{1}$
}

Received: 21 February 2016/Accepted: 17 May 2016/Published online: 21 June 2016

(C) Society for Experimental Mechanics, Inc 2016

\begin{abstract}
The deformation response of welded aluminum plate was evaluated at high and low strain rates. Mechanical and ballistic experiments were conducted on $2.5 \mathrm{~cm}$ thick samples obtained from full penetration welds for welded aluminum 5083-H131 plate. Similar experiments were also conducted for the aluminum 5083 alloy as a baseline for comparison. Experiments were designed to compare the deformation response and ballistic performance differences for fusion welds versus friction stir welds. The fusion welds were processed using gas metal arc welding. The low strain rate deformation response was evaluated with three-point bend tests at an approximate strain rate of $1 \mathrm{~s}^{-1}$. The high strain rate response of the three materials was assessed using ballistic impact experiments at a range of velocities. Digital image correlation analysis was applied to gain insight into the deformation response through quantification of the strain and deflection profiles. The deformation response differences are compared for the welds versus the baseline aluminum alloy.
\end{abstract}

Keywords Welds - Aluminum alloys - Deformation response $\cdot$ Ballistic experiments $\cdot$ Digital image correlation

\section{Background}

Aluminum alloys are being used increasingly in military vehicles owing to their low density, corrosion resistance, relatively low cost compared to alternative lightweight

Kathryn A. Dannemann

kathryn.dannemann@swri.org

1 Southwest Research Institute, PO Drawer 28510, San Antonio, TX 78228, USA metallic materials and high performance against various threats [1-5]. Aluminum (Al) alloy 5083-H131, the subject of this investigation, has been used in military vehicles in accordance with the specification for welded aluminum armor plate [6]. Al 5083 is a non-heat treatable alloy with moderately high strength, very high toughness and excellent corrosion resistance. It can be readily welded using various techniques even for relatively thick plates. This contributes to the appeal of $\mathrm{Al} 5083$ compared to higher strength aluminum alloys that are not as readily welded. The H131 temper designates that the alloy is strain hardened (cold worked) to achieve moderate strength. The hard H131 temper is applicable to armor plate and differs from the H116 temper, a marine grade temper, for which characterization results have been published previously [7].

Conventional welding methods (e.g., gas metal arc welding, GMAW) utilize a filler metal to join materials, and have been employed for joining aluminum in military armor structures. Alternative joining techniques (e.g., friction stir welding) have become more feasible for vehicle applications owing to significant advancements in welding technologies [8]. Friction stir welding (FSW) of aluminum alloys shows promise for various military applications [9-13]. This welding technique allows retention of ballistic protection; the costs are reduced relative to conventional welding processes. FSW is a solid-state joining process invented by The Welding Institute (TWI), Cambridge, United Kingdom in 1991 [14]. During the welding process, metal in the vicinity of the joint is softened, but not melted. FSW process improvements have been implemented since its initial introduction. Research and development in FSW, and related technologies (e.g., friction stir processing), have advanced FSW as a joining procedure for low melting point metals: aluminum, copper and magnesium alloys. The efficacy of this joining 
technique is evident from the continual increase in the number of technical papers, review articles [8, 15, 16], books [17] and conferences [18] on this subject. Progress has also been made on friction stir welding of higher temperature alloys (e.g., titanium, steels, and nickel alloys), and dissimilar alloys and metals [19, 20].

\section{Introduction}

Friction stir welded aluminum alloys have been investigated extensively to better understand the response of the weld material. The microstructure and mechanical properties of various friction stir welded aluminum alloys have been evaluated to determine the strength of the weld metal and the extent of property degradation, if any, versus the base material. Generally, the strength of friction stir welds is similar to that of the base material and is related to the lower heat input for this solid-state joining process. Fusion welds produced with traditional welding processes generally have reduced properties compared to the base material, owing to the use of lower strength filler metals and a propensity for welding defects (e.g., cracking, porosity).

The mechanical response of Al 5083 and Al 6082, a heat treatable alloy, was investigated by Svensson, Karlsson, et al. [21]. For Al 5083 FSW welds, approximately constant hardness was observed across the welds; fracture occurred near the center of the weld. For the Al 6082 FSW, fracture occurred mainly in the heat affected zone (HAZ) at regions of minimum hardness. The tensile strength of the Al 6082 FSW was less than the base material strength. Findings for several other friction stir welded aluminum alloys (Al 2519-T87, Al 7075-T651, Al 2139-T8) also demonstrate good strength retention. In contrast to $\mathrm{Al}$ 5083 , these alloys are strengthened by heat treatment. For Al 2519-T87, some strength reduction was reported in the FSW region [22]. Softening was observed at the TMAZ (thermo-mechanically affected zone)/HAZ boundary, and was attributed to coarsening and transformation of the strengthening precipitates during the welding process. For the Al 7075-T651 alloy, the HAZ was found to be the weakest region associated with the FSW [23]. Although reductions in yield and ultimate strengths were measured, the losses due to the FSW process were at the lower end of the range typically observed for weldable Al alloys. In-situ testing of Al 2139-T8 FSW in a scanning electron microscope revealed distinct differences for specimens from the weld region versus outside the weld region [24]. The differences were attributed to varying plastic deformation, recrystallization and recovery in the stir zone region of the weld.

The behavior of fusion and friction welds during impact and other dynamic events is of interest for military applications. The effect of strain rate on the response of welded aluminum alloys has not been as widely reported. The strain rate sensitivity of aluminum alloys is dependent on the specific alloy and temper. Some aluminum alloys exhibit a negative strain rate effect (i.e., lower strength at higher strain rates) [25]. Most investigations to date on the dynamic response of aluminum alloys joined by friction stir welding have been conducted on small specimens excised from welds and weld regions (HAZ, TMAZ) versus testing of welded specimens [26, 27]. The effect of friction stir welding on the dynamic compression properties of $\mathrm{Al}$ 2024-T3 and Al 7075-T7351 alloys was evaluated using a Hopkinson/Kolsky bar at strain rates approaching $1200 \mathrm{~s}^{-1}$ [27]. A strain rate effect was reported; FSW reduced the yield strength of both alloys versus the base metal. Gunarsson, et al. [28] utilized welded specimens to investigate the tensile response of friction stir welded $\mathrm{Al}$ 2139-T8 as a function of loading rate and stress state at low and intermediate strain rates; modified three-point bend experiments were conducted at high strain rate with a Kolsky bar. The response of the welded plate was investigated as a whole versus individual weld zones. A digital image correlation (DIC) strain measurement method, similar to the approach reported by Dannemann, et al. [29, 30] for fusion welded Al specimens, was used to detect strain concentrations in the FSW during loading with a traditional loadframe and with a Kolsky bar. Most recently, the quasistatic and dynamic tension response of welded (FSW and gas tungsten arc weld, GTAW) specimens were investigated for two different aluminum alloys: Al 5182-O (nonheat treatable) and Al 6111-T4 (heat treatable) [31]. The gage section of thin sheet, welded specimens consisted of nearly $100 \%$ weld. The results of Hopkinson bar tensile tests at approximate strain rates of $10^{2}$ to $10^{3} \mathrm{~s}^{-1}$ show minimal strain rate sensitivity for the FSW Al 5182-O materials and positive strain rate sensitivity for FSW Al 6111-T4.

Progress has been made towards understanding the quasi-static and dynamic mechanical response of friction stir weld materials. However, limited results have been reported that address the ballistic response of friction stir welds and the comparative response of fusion welds. A decrease in penetration resistance was reported for FSW Al 2050-T8 during direct ballistic impact of the weld region; almost no loss of penetration resistance was observed for impact of the HAZ region [32]. Sullivan, et al. [33] conducted ballistic experiments, microstructural investigations and numerical simulations to systematically study the link to microstructural variations in friction stir welds in high strength aluminum plate (Al 7010-T651). The ballistic response of friction stir processed (FSP) materials has been evaluated also. FSP is a microstructural modification technique adapted from the concepts of FSW that refines 
the grain structure and improves the mechanical properties. Initial results for FSP Al 6019-T4 showed improved energy absorption versus the parent material, and formation of adiabatic shear bands during ballistic loading [34]. The effect of the FSP technique on the performance of armor grade aluminum ( $\mathrm{Al} 6061$ and $\mathrm{Al} 7039$ ), and high strength low alloy steel (HSLA), was further investigated by Johnson, et al. [35]. HSLA FSP material showed an increase in the $\mathrm{V}_{50}$ ballistic limit velocity over the parent material. Thick aluminum alloys processed with FSP showed softening and a lower $V_{50}$ than the parent material. $\mathrm{V}_{50}$ testing identifies the average velocity at which a projectile or fragment penetrates the target in $50 \%$ of the shots; penetration does not occur in the other $50 \%$.

Knowledge of the overall weld response is critical for understanding the behavior of welded joints in ballistic and high strain rate applications. Few studies conducted to date provide a direct comparison of the ballistic and impact response of friction stir welds versus fusion welds. Hence, this comparative study was undertaken to assess differences in weld response between GMAW and FSW at high and low strain rates. The experiments were performed on full size $(2.5 \mathrm{~cm}$ thick $)$ welded specimens of $\mathrm{Al}$ 5083-H131. A DIC technique was used to assess the weld response differences and to quantify strain differences in the weld during impact. DIC is a useful tool for evaluating the three-dimensional deformation and strain response, especially in non-homogeneous materials like welds. It provides a non-contact measurement of strain during dynamic deformation. Recent advancements have occurred over the last decade in applying DIC technology to improve understanding of the mechanical response of various engineering structures. The technique is applied to improve understanding of the weld response and assess differences that occur during impact of fusion and friction stir welds in armor grade aluminum 5083.

\section{Materials}

The aluminum 5083-H131 alloy was selected for evaluation. This includes full size welds for $2.5 \mathrm{~cm}$ thick plate. The Al 5083 alloy is of interest for military applications owing to its light weight and relative welding ease.

The Al 5083-H131 plate material $(2.5 \mathrm{~cm}$ thick) obtained was in accordance with ASTM B209 [36]. The fusion welds were fabricated by Onodi Tool and Engineering (OTE) using the GMAW pulse method. The fusion welds were fabricated in accordance with the ground vehicle combat welding code for aluminum. The GMAW weldments used a double V-groove weld with a $60^{\circ}$ included angle $\left(30^{\circ}\right.$ each side). and were welded in the flat position. A representative cross-section through one of the
GMAW specimens is shown in Fig. 1a. The weldcap is milled flat on both sides of the fusion weld in this image. The FSW weldments were fabricated by Concurrent Technologies Corporation (CTC). A butt joint design was used for the FSW complete penetration welds. All FSW weldments were welded in the flat position and according to AWS D17.3 [37]. A representative friction stir weld profile is shown in Fig. 1b. The ballistic targets and bend test specimens were sectioned from long $(\sim 122 \mathrm{~cm})$ welded plates with the centerline of the weld parallel to the long axis of the plate. The ballistic targets measured $30 \mathrm{~cm} \times 30 \mathrm{~cm} \times 2.5 \mathrm{~cm}$, with the weld centered across the entire plate. The bend test specimens measured $30 \mathrm{~cm} \times 5 \mathrm{~cm} \times 2.5 \mathrm{~cm}$, and were provided by OTE. For the bend samples, the welds were located at the center of the $30 \mathrm{~cm}$ length and spanned the $5 \mathrm{~cm}$ specimen width. Ballistic targets and bend specimens for the aluminum 5083 base alloy were also sectioned from the $2.5 \mathrm{~cm}$ thick plate, prior to welding, to provide a baseline for comparison with the welded test specimens. The layout and orientation of the welded plates and test specimens is illustrated in the schematic in Fig. 2.

\section{Experimental Procedure}

Experiments were designed to provide a direct comparison of the mechanical and ballistic performance differences for fusion and friction stir welds. Both low (laboratory bend tests) and high (ballistic tests) strain rate experiments were conducted. The three-point bend experiments were conducted initially to assess deformation at a slower rate $\left(\sim 1 \mathrm{~s}^{-1}\right)$. A three-point bend test setup was selected over a four-point setup as it provides more stress localization. Since ballistic testing imparts localized stresses at the location of projectile impact, the three-point bend experiments also allowed confirmation of the DIC technique for subsequent application with the high strain rate $\left(\sim 10^{4} \mathrm{~s}^{-1}\right)$ ballistic tests. Similar experiments were conducted for welded specimens, as well as the Al 5083-H131 base alloy for comparison. Prior to initiating testing, numerical simulations of the experiments were performed to aid with experimental design for both types of tests.

\section{Mechanical Experiments}

All bend tests were conducted using a traditional MTS load frame, equipped with a $222 \mathrm{kN}(50,000 \mathrm{lb})$ load cell. All experiments were conducted at a machine displacement rate of $0.03 \mathrm{~mm} / \mathrm{s}$, corresponding to an approximate strain rate of $1 \mathrm{~s}^{-1}$. A three-point bend fixture was designed and assembled for testing the $2.5 \mathrm{~cm}$ thick specimens; a loading span of $20 \mathrm{~cm}$ was employed for all bend tests. The test 
Fig. 1 Weld profiles a fusion weld and $\mathbf{b}$ friction-stir weld. The arrow in b shows the direction of projectile impact
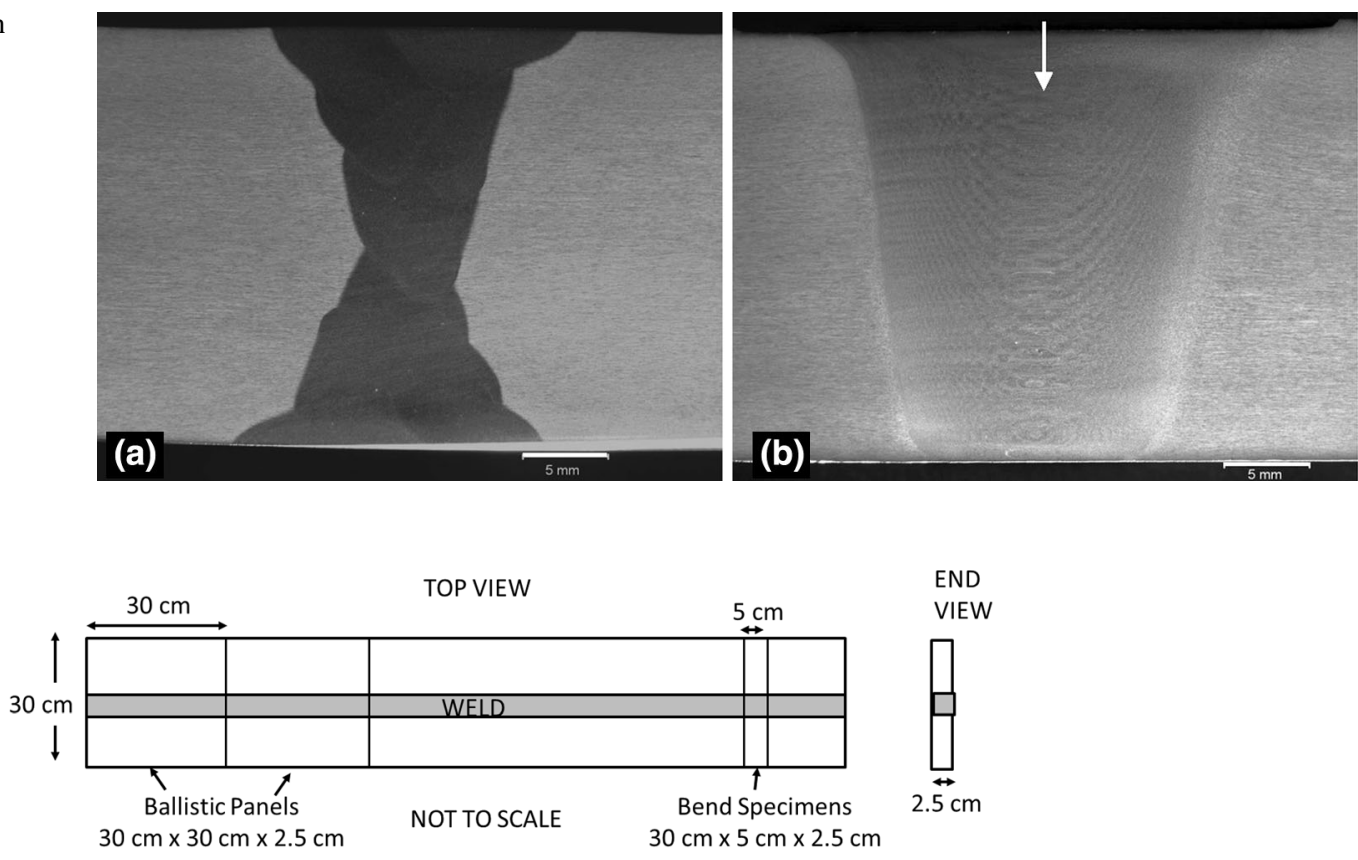

Fig. 2 Schematic of a welded plate (top view), showing the size and orientation of ballistic targets and bend test specimens relative to the weld. All specimens were excised from the full thickness $(2.5 \mathrm{~cm})$ plates

fixture is shown in Fig. 3. Load and crosshead displacement were recorded during each test. The setup was coordinated with camera location to ensure accessibility for photographing during loading to obtain images for DIC analyses.

Six bend tests were conducted per material type (GMAW, FSW, base alloy) at increasing levels of displacement up to a maximum of $3.35 \mathrm{~cm}$. An additional setup test was also conducted on Al 5083 with a $3.8 \mathrm{~cm}$ wide specimen (versus $5.1 \mathrm{~cm}$ for all other tests). Specimen images were recorded during loading, and subsequently analyzed with DIC software to estimate deflections and specimen strains. The weld region of the GMAW specimens was milled on both sides of the weld prior to testing. This provided a more consistent surface finish and minimized possible slippage under the loading pin in the weld region. The smooth surface also provided a consistent starting condition for strain measurements using DIC analysis. Extreme care was exercised throughout the bend experiments. However, it is worth noting that some of the GMAW bend specimens provided had inconsistent dimensions with cross-sections approaching a trapezoidal shape instead of rectangular. These were replaced with additional bend test specimens sectioned from the same welded plates and machined at the SwRI machine shop; tighter dimensional tolerances were obtained for this group of GMAW specimens. No additional surface preparation was performed on bend specimens for the FSW and baseline aluminum materials. Milling of the FSW specimens was not necessary as the weld surface was smoother and more consistent than for the GMAW specimens.
Fig. 3 Bend test setup. a Test fixture, $\mathbf{b}$ magnified view of test fixture and aluminum specimen with dot pattern for imaging
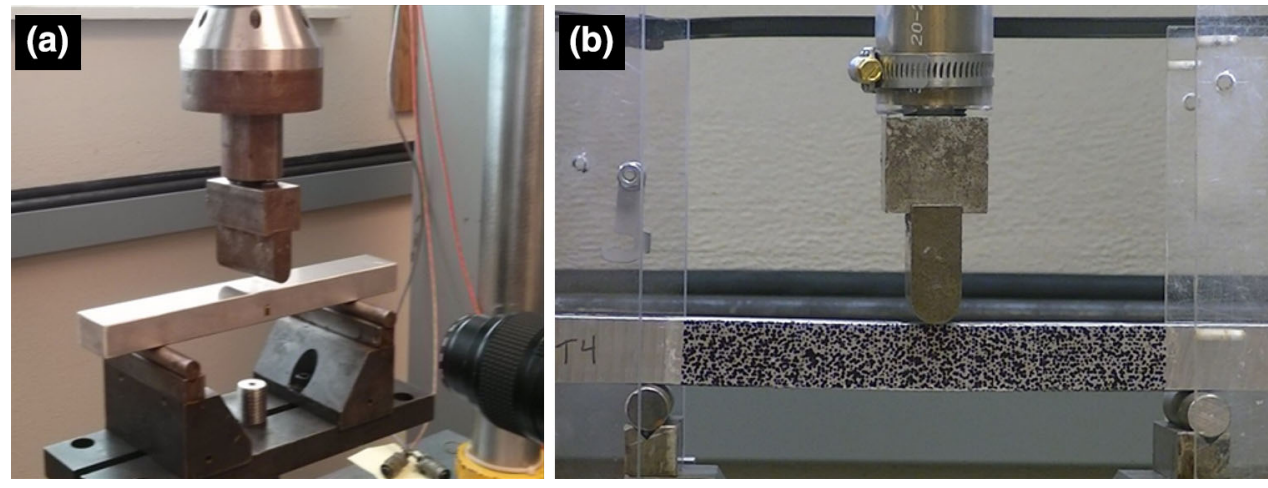
Fig. 4 Ballistic test setup. a Overall setup with target, two high speed cameras, mirrors and lighting. The cameras were positioned to obtain images of the back face of the target during impact. b Each target is attached to a metal frame prior to testing. c A dot pattern was applied to the back of each target for digital image correlation analysis
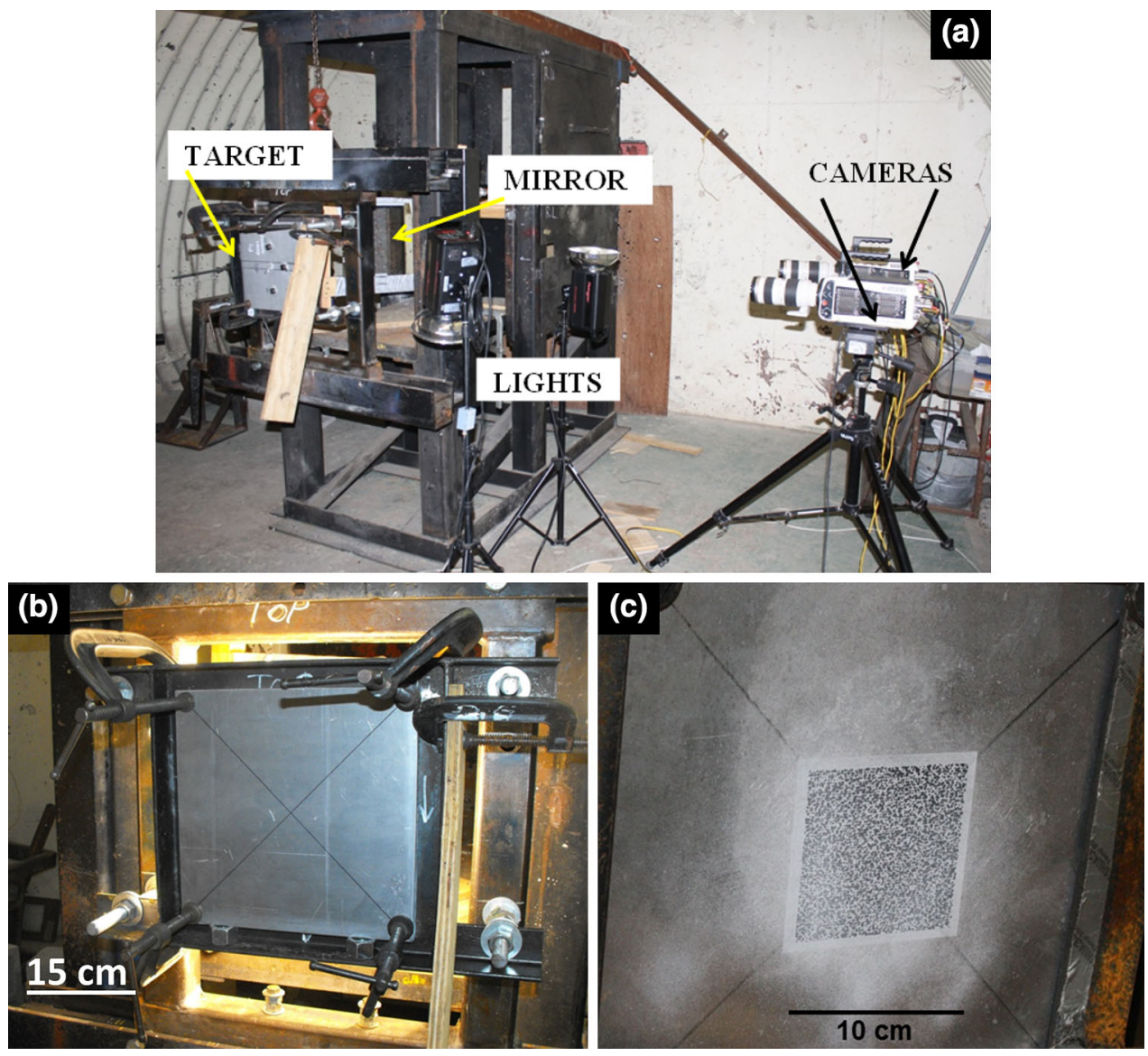
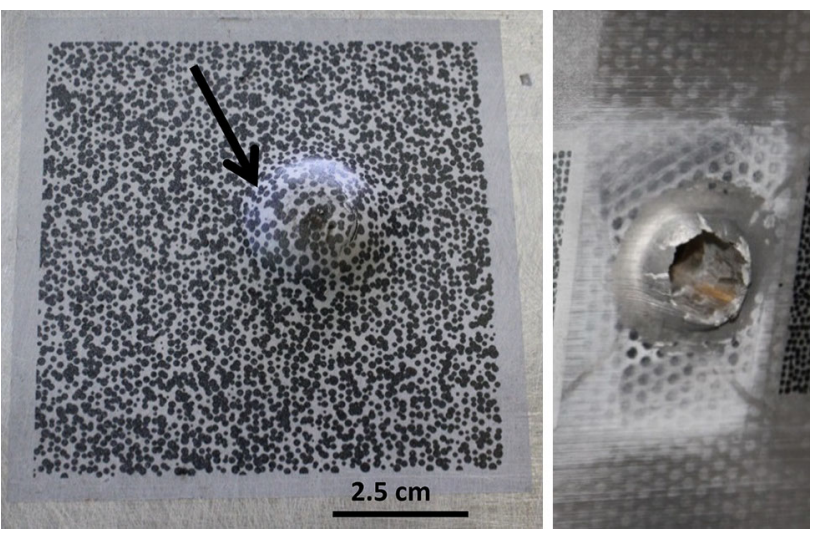

Fig. 5 Target deformation following ballistic impact. A spraypainted pattern (right) was used for initial tests. Customized decals (left) were implemented for subsequent tests to overcome paint adherence issues (right) due to extreme deformation. Adherence of the decal pattern was maintained throughout the entire deformation process

A dot pattern was applied to the tensile surface (bottom) and the adjacent (through-thickness) side of each specimen for effective DIC measurements and analysis. A representative dot pattern is shown in Fig. $3 \mathrm{~b}$ on the side surface of the bend specimen. The pattern was easily applied to both specimen surfaces using custom-made decals. This technique was perfected for the ballistic test specimens, which were prepared and tested before completing the bend experiments. Much effort was applied to the patterning of the ballistic panels owing to the very ductile deformation process that occurred, resulting in bulge formation prior to target failure and large resulting strains. Additional info on this technique is provided in the "Ballistic Experiments" section.

Numerical simulations of the three-point bend test were performed to estimate the extent of deflection during loading. The results were also used to aid with machine and camera setup to ensure sufficient displacement range and camera access. All simulations were conducted with LSDYNA, a commercial finite element code. The material constitutive behavior was simulated using a Johnson-Cook (J-C) model. The $\mathrm{J}-\mathrm{C}$ constitutive model includes strain rate and temperature effects and is described in the classic paper by Johnson and Cook [38]. Three different material types were evaluated: (1) Al 5083-H131 base alloy, (2) FSW, and (3) GMAW specimens. The simulation results showed higher strains for a shorter span length (i.e., $20 \mathrm{~cm}$ vs. $25 \mathrm{~cm}$ ), as expected from beam theory. The numerical simulations confirmed that the maximum load attained for the $20 \mathrm{~cm}$ span was within the load cell capacity of the 
machine. The simulations also showed fracture of the aluminum baseline material did not occur for large deflections $(\sim 7 \mathrm{~cm})$.

\section{Ballistic Experiments}

Ballistic experiments were conducted to compare the impact performance of the welds and base alloy against a $20 \mathrm{~mm}$ fragment simulating projectile (FSP). The $20 \mathrm{~mm}$ FSP's were machined from 4340 steel and heat treated to a hardness value of Rockwell C30. The projectile is a bevelnosed cylinder with a small skirted base that is used to engage the barrel rifling. All ballistic testing was conducted at the SwRI indoor medium caliber test facility, located on the San Antonio main campus. The projectiles were launched using a rifled $20 \mathrm{~mm}$ barrel held in a universal gun mount. A bore mounted laser was used to align the gun with the desired impact location on the target and to confirm target obliquity. The breech volume was adjusted to account for the low impact velocities. This allowed a more consistent propellant burn due to the low fill rates.

The experiments were conducted at a range of impact velocities. Impact velocities both above and below $V_{50}$ were employed to allow investigation of deformation and failure. Projectile impact velocities were measured using two sets of photoelectric chronographs located between the gun mounts and the target fixture. The spacing between each set of chronographs was $1.22 \mathrm{~m}$. Calibrated HP universal counters, triggered by the chronographs, recorded
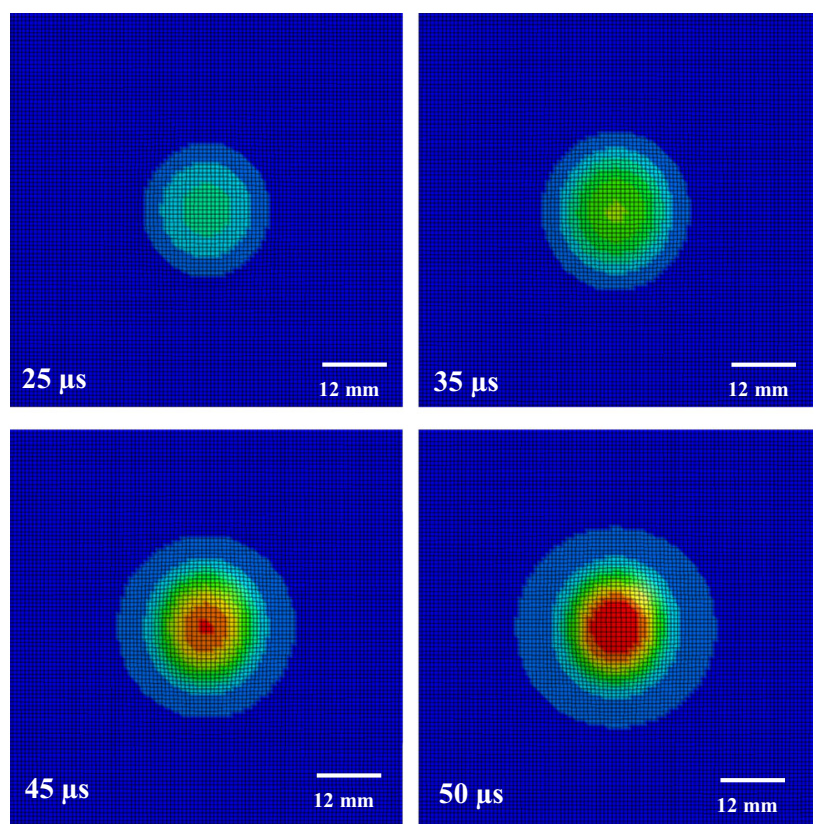

Fig. 7 Displacement of back face of target at velocity of $1.1 \mathrm{~V}_{50}$. The maximum deformation scale (color profile) is $0-0.5 \mathrm{~cm}$

the time for the projectile to travel between chronographs. Projectile velocity was then calculated using the recorded times and the known travel distance. An average of the two calculated velocities was recorded as the screen velocity. Due to the non-ideal shape of the FSP's, a reduction factor was applied to the measured speeds to account for velocity loss between the screens and target frame.
Fig. 6 Numerical modeling results show penetration of $2.5 \mathrm{~cm}$ thick $\mathrm{Al} 5083$ plate at a velocity of $1.05 \mathrm{~V}_{50}$

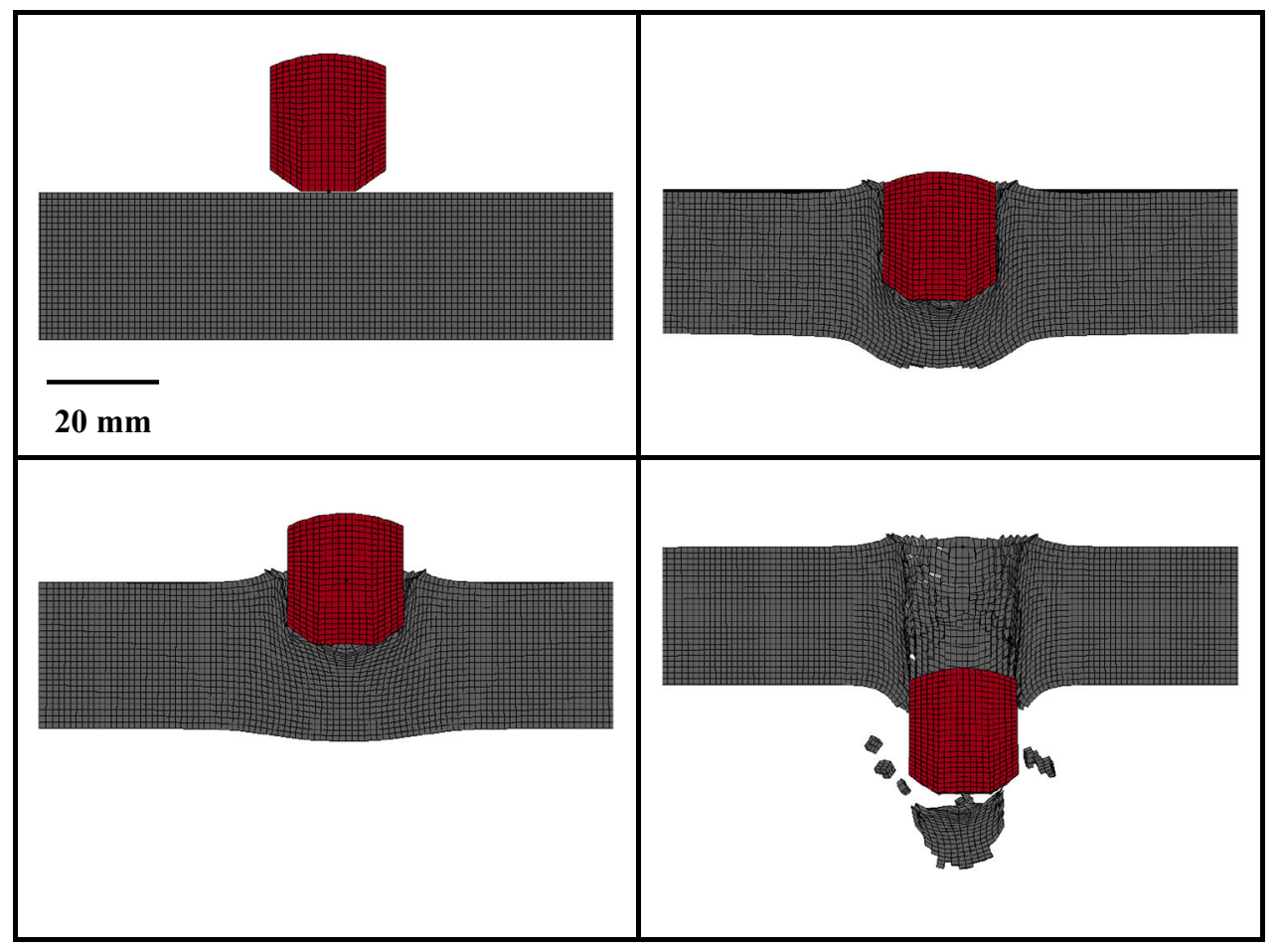


The ballistic test setup is shown in Fig. 4. Each ballistic target was clamped to a rigid steel frame and oriented to ensure it was normal to the advancing projectile. A square opening in the frame (see Fig. 4b) allowed unconstrained deformation of the aluminum target during impact, and access for imaging the rear target surface (Fig. 4c). Common C-clamps were used in each corner of the sample to secure each target to the frame. Ballistic tests were conducted at a range of velocities, resulting in minimal impact of the target through full penetration. Twenty-eight ballistic tests were conducted: ten per weld type and eight for the baseline $\mathrm{Al}$ alloy.

The GMAW targets were milled on the rear (non-strike face) of each panel prior to testing to remove the weld cap. The smooth surface provided a consistent starting condition for strain measurements. The weldcap on the strike face of the ballistic targets was not milled to maintain conditions more representative of the actual application. Milling of the FSW targets was not necessary owing to the relative smoothness of these panels. The direction of projectile impact for the FSW panels is shown by the arrow in the FSW photo in Fig. $1 b$.

Table 1 Bend test summary

\begin{tabular}{llllll}
\hline $\begin{array}{l}\text { Test } \\
\text { No. }\end{array}$ & Type & $\begin{array}{l}\text { Max } \\
\text { load } \\
(\mathrm{kN}) *\end{array}$ & $\begin{array}{l}\text { Machine } \\
\text { deflection } \\
(\mathrm{cm})\end{array}$ & $\begin{array}{l}\text { DIC } \\
\text { strain } \\
(\text { Max } \%)\end{array}$ & $\begin{array}{l}\text { Strain/ } \\
\text { deflection } \\
\text { ratio }(\% / \mathrm{cm})\end{array}$ \\
\hline T2 & Al 5083 & 71.30 & 3.61 & 21.3 & 5.91 \\
T6 & Al 5083 & 72.92 & 2.39 & 16.4 & 6.87 \\
T11 & Al 5083 & 68.58 & 1.57 & 10.1 & 6.41 \\
T17 & Al 5083 & 71.79 & 2.24 & 15.2 & 6.80 \\
T18 & Al 5083 & 74.83 & 3.35 & 23.0 & 6.86 \\
T19 & Al 5083 & 75.85 & 3.35 & 23.1 & 6.89 \\
& & & & Mean-Al & 6.62 \\
T3 & FSW & 51.99 & 1.68 & 9.7 & 5.79 \\
T7 & FSW & 59.30 & 2.95 & 15.8 & 5.36 \\
T8 & FSW & 60.84 & 3.30 & 20.5 & 6.21 \\
T10 & FSW & 61.66 & 3.35 & 18.9 & 5.64 \\
T12 & FSW & 61.17 & 3.35 & 18.8 & 5.61 \\
T13 & FSW & 60.85 & 3.35 & 19.6 & 5.85 \\
& & & & Mean-FSW & 5.74 \\
T4 & GMAW & 56.37 & 2.29 & 20.1 & 8.79 \\
T5 & GMAW & 55.14 & 2.54 & 25.0 & 9.84 \\
T9 & GMAW & 42.34 & 1.52 & 13.5 & 8.86 \\
T14 & GMAW & 59.05 & 3.35 & 27.5 & 8.20 \\
T15 & GMAW & 57.77 & 3.35 & 27.7 & 8.26 \\
T16 & GMAW & 57.96 & 3.35 & 26.9 & 8.02 \\
& & & & Mean-GMAW & 8.66 \\
\hline
\end{tabular}

* Maximum load prior to specimen unloading

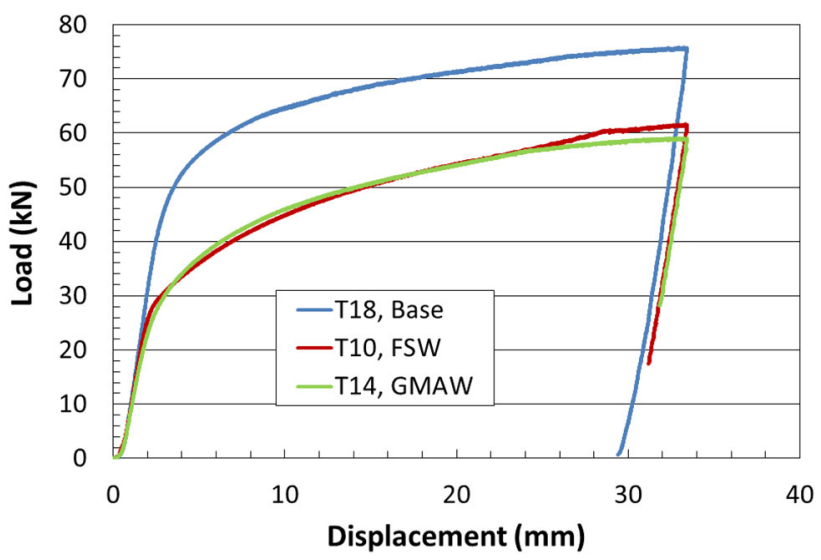

Fig. 8 Load versus machine displacement comparison for baseline Al 5083, FSW and GMAW specimens loaded to similar deflection levels $(3.35 \mathrm{~cm})$
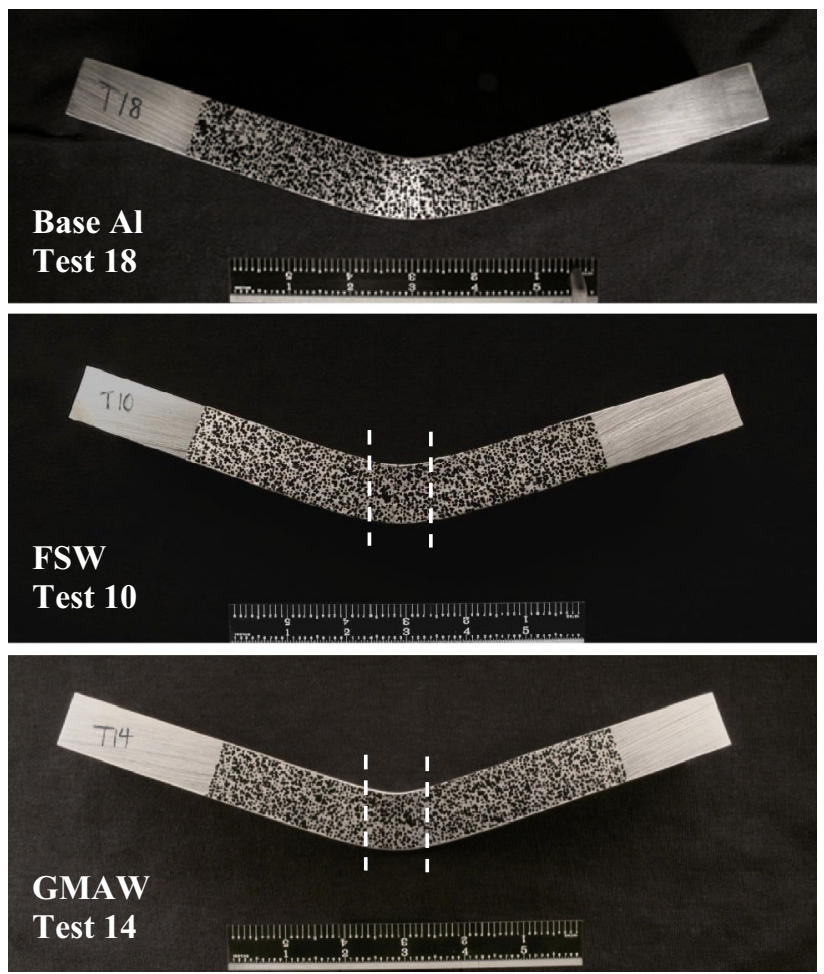

Fig. 9 Representative bend specimen profiles for: baseline, GMAW and FSW materials following three-point bend testing. The post-test profiles are for the specimens depicted in Fig. 8. Dotted lines mark the weld region; the scale is in inches

Much effort was applied to patterning of the target panels to ensure that the entire deformation pattern could be captured for DIC analysis. Initially, a painted dot pattern was used for DIC patterning. Pattern adherence issues were observed with the painted pattern due to the extensive deformation that occurred during impact of each material type. A $2.5 \mathrm{~cm}$ thick Al 6061 target panel with various patterns was impacted and evaluated to improve the images 


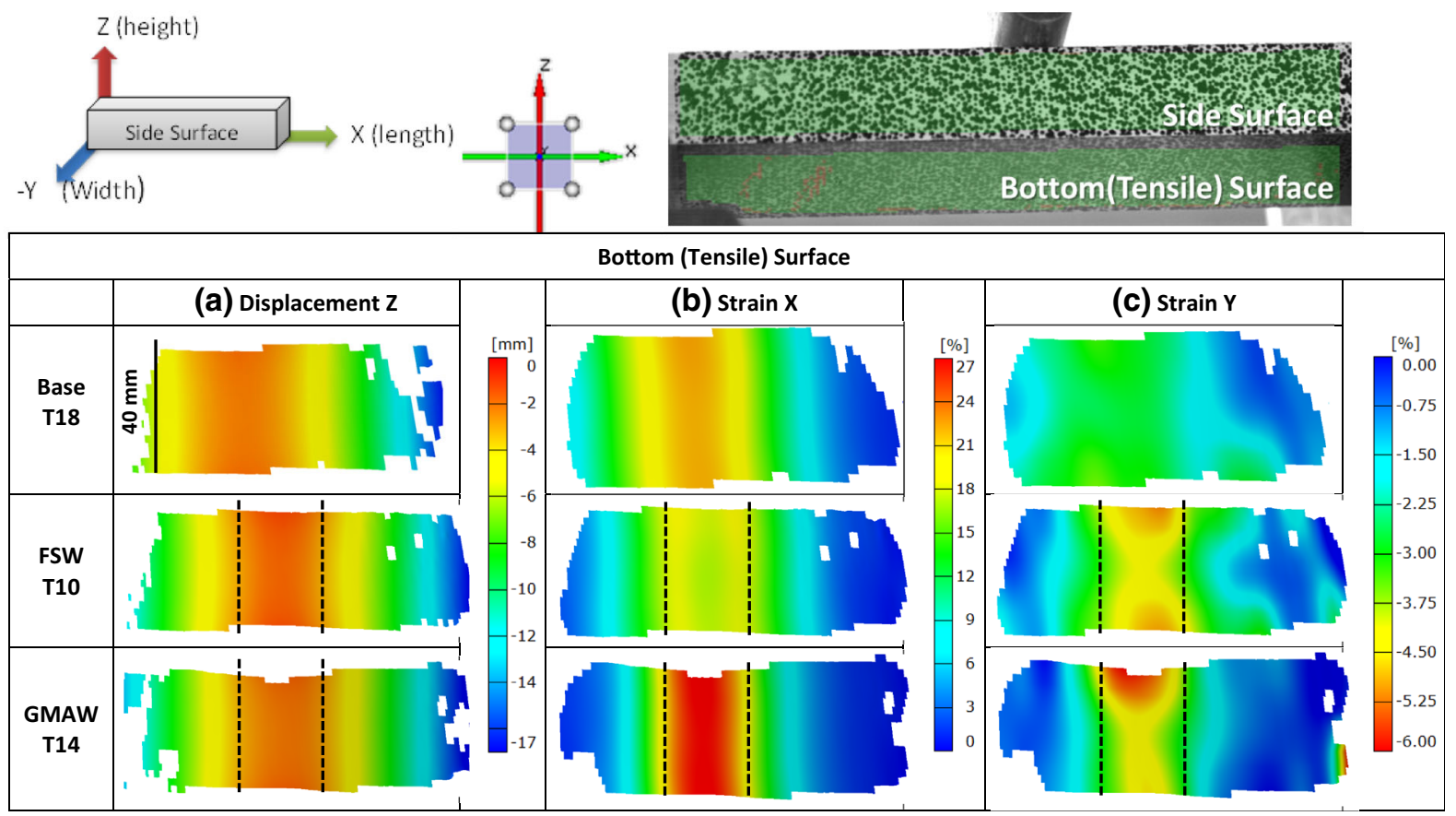

Fig. 10 Displacement and strain maps for the tensile (bottom) surface of the bend test specimens shown in Figs. 8 and 9. Each specimen was loaded to a similar machine displacement. a Z-
Displacement, b strain in the X-direction (length), c strain in the Y-direction (width). Dotted lines mark the weld regions

material. The extents of these regions within the meshes were set to match those measured from metallurgical evaluation of the GMAW and FSW materials (see Fig. 1).

A simple linear elastic material model was used for the outer areas of the plate. The center portion of the target plate near the impact location utilized a full Johnson-Cook strength and damage model for the steel, aluminum and FSW. Since constitutive parameters were not readily available for the GMAW, the strength of the weld itself was assumed to be equal to that of the base material, while the HAZ for the GMAW weld utilized similar parameters with a $40 \%$ knockdown to the strength of the base material. Numerical simulation results for a velocity exceeding $\mathrm{V}_{50}\left(1.05 \mathrm{~V}_{50}\right)$ are illustrated in Figs. 6 and 7. The figures demonstrate the extent of penetration for this velocity, and the displacement at the rear of the target as a function of time after impact.

\section{Digital Image Correlation Analysis}

A digital correlation (DIC) system was used to evaluate deformation (i.e., deflection and strain) response differences for both types of experiments. This is an ideal application of DIC as it allows for measurement of the strain field across the weld during impact, and loading. The ARAMIS system used for these tests is a high-speed (60 Hz to $250,000 \mathrm{~Hz}$ ) 3D-DIC system. Data was captured 


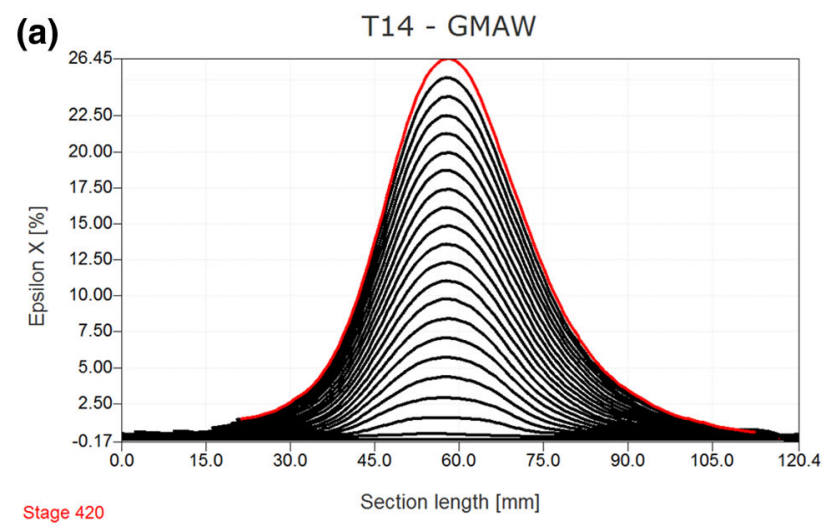

(b)
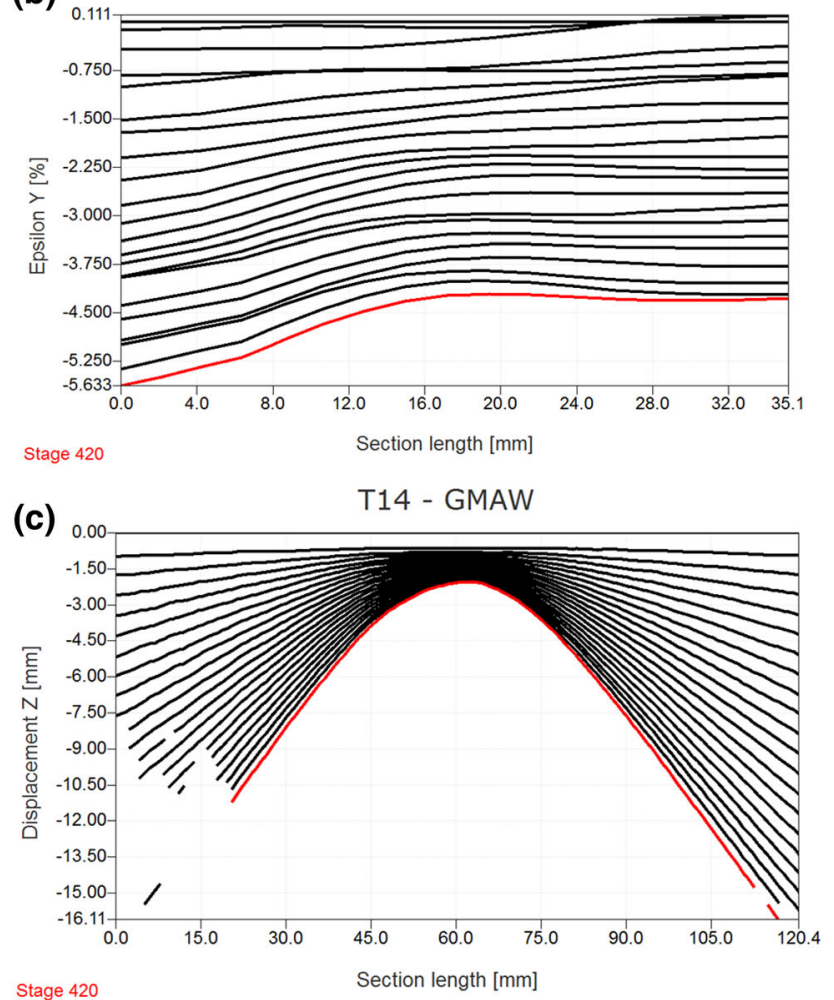

Fig. 11 Strain and displacement profiles measured with DIC for a GMAW bend specimen (T14). The red curve indicates the final stage before unloading. a Strain in the X-direction along the specimen length, b strain in the Y-direction plotted versus the specimen width, c displacement in the $\mathrm{Z}$ (thickness)-direction plotted versus the specimen length. Reference frame for Z-displacement is the centerline of the tensile surface

using a stereo pair of high-speed video cameras (Phantom ${ }^{\circledR} \mathrm{v} 711$ ), positioned with a small angle between them. Images of the deformation from the camera pair were combined with a set of calibration images in DIC software to produce deflection and strain data, and their timederivatives.
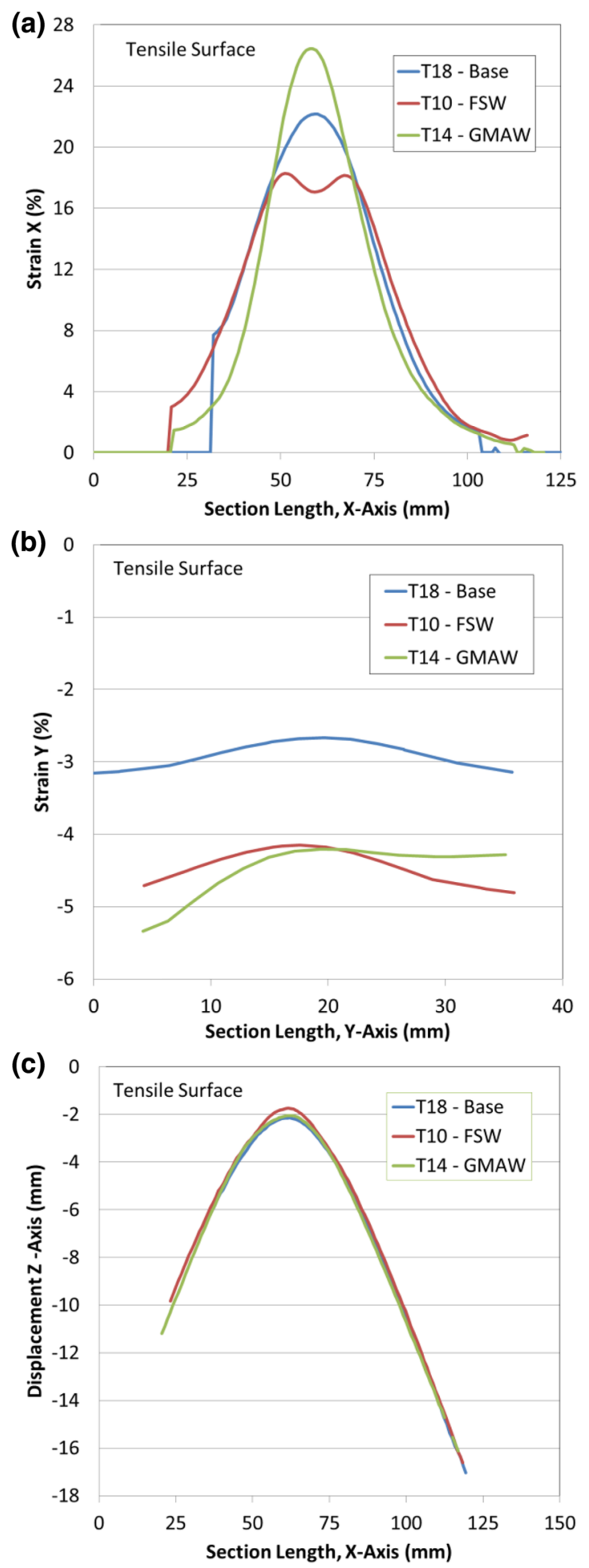

Fig. 12 Strain and displacement comparisons for the bend test specimens shown in Fig. 8 at the final time step. The profiles are for the bottom (tensile) surface of the specimens. a $\varepsilon_{\mathrm{x}}$ along the specimen length, $\mathbf{b} \varepsilon_{\mathrm{y}}$ across the specimen width, $\mathbf{c}$ Z-displacement along the specimen length, at the centerline 

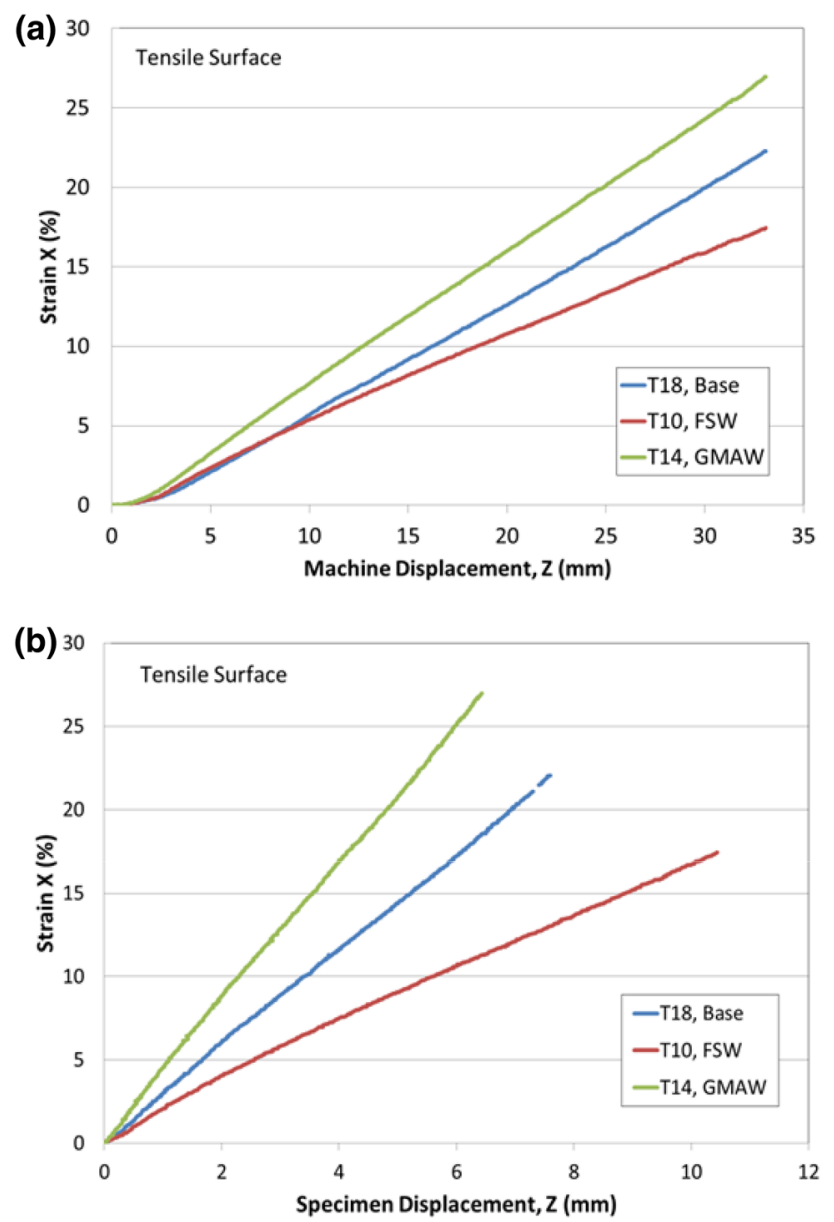

Fig. 13 Comparison of $\varepsilon_{\mathrm{x}}$ strain versus displacement (Z-direction) for representative FSW, GMAW and Al 5083 specimens. These are for the bottom/tensile surface. a $\varepsilon_{\mathrm{x}}$ versus crosshead/machine displacement, b $\varepsilon_{\mathrm{x}}$ versus specimen displacement from DIC measurements

For the ballistic tests, the back (non-strike face) of each target panel was monitored during projectile impact. The tensile and side surfaces of the bend specimens were monitored during loading. Prior to testing, a semi-random dot pattern was applied to each specimen using a customized decal and a misted paint overlay. Dot patterns applied with more traditional methods (i.e., spray paint, markers) were not as effective as they disappeared during testing owing to extensive deformation of the aluminum. For the ballistic tests, full-field deflections and strains (at approximately 4000 locations per test) were measured at rates of $100,000 \mathrm{~s}^{-1}$. The stereo camera pair for the ballistic tests was positioned to the side of the target, as shown in Fig. 4a. Deflections on the back face of the target were imaged using a mirror. The system was set to measure deflections up to $15 \mathrm{~cm}$, but during testing the deflections observed tended to be much less. For higher impact velocities, target plugs were ejected and could be tracked as they exited the target and their ejection speed measured.
For the bend tests, images were recorded at 24 to 48 frames per second. Approximately 3000 locations were evaluated on the tensile surface of the bend specimens and 5000 on the side surface.

\section{Results and Discussion}

\section{Mechanical Experiments}

The bend test results were evaluated to determine the extent of deformation response differences for the three materials of interest. The test results are summarized in Table 1 for six tests per material type (GMAW, FSW and $\mathrm{Al}$ 5083). The table includes: maximum load and machine crosshead displacement prior to unloading, as well as the maximum strain on the tensile surface of the specimen. The maximum strain was determined with DIC analysis. The ratio of maximum strain to machine crosshead displacement is listed in the last column of Table 1 .

The load-displacement curves obtained showed good consistency for each group of materials. Some variability was observed for the initial tests on the GMAW specimen group. This is attributed to weld variability and curvature, and some inconsistencies in the specimen dimensions for the initial bend specimens provided. Additional GMAW specimens were sectioned from the same welded plate and machined in the SwRI machine shop. Tighter dimensional tolerances were obtained for GMAW specimens prepared by SwRI. The results for tests on these specimens (Tests T14, T15 and T16) demonstrated more consistent loaddisplacement curves. Representative load-displacement curves for the three different material types are compared in Fig. 8; post-test images of these specimens are shown in Fig. 9. The specimens represented in the plot were loaded to similar machine displacement levels $(3.35 \mathrm{~cm})$. A comparison of the load-displacement curves indicates that the base $\mathrm{Al}$ 5083-H131 alloy can accommodate higher loads than the weld materials at the same deflection levels. The two different types of welds, FSW and GMAW, exhibited similar load-displacement response. However, a higher slope of the load-displacement curves was exhibited for the FSW specimens versus GMAW specimens as the maximum displacement level was approached. The welded bend specimens exhibited some contraction across the specimen width during loading. This is attributed to the softer material in the weld zone, as it was not observed for the baseline $\mathrm{Al}$ specimens.

DIC analysis of the bend test specimens revealed deformation response differences for the weld specimens versus baseline aluminum specimens. The differences are apparent upon comparison of representative strain and displacement maps shown in Fig. 10. These maps were 
Table 2 Ballistic test summary

\begin{tabular}{|c|c|c|c|c|c|c|c|c|c|c|}
\hline \multirow[t]{2}{*}{ Test No. } & \multirow[t]{2}{*}{ Specimen type } & \multirow{2}{*}{$\begin{array}{l}\text { Normalized } \\
\text { velocity }\end{array}$} & \multicolumn{3}{|c|}{ Peak strain $(\%)$} & \multicolumn{3}{|c|}{ Strain at impact point $(\%)$} & \multirow{2}{*}{$\begin{array}{l}\text { z-deflection } \\
(\mathrm{mm})\end{array}$} & \multirow[t]{2}{*}{ Result } \\
\hline & & & $\varepsilon_{\mathrm{x}}$ & $\varepsilon_{\mathrm{y}}$ & Avg & $\varepsilon_{\mathrm{x}}$ & $\varepsilon_{\mathrm{y}}$ & Avg & & \\
\hline 16 & Al 5083 & 0.911 & 20 & 22 & 21.0 & 17 & 18 & 17.5 & 6.4 & Pass, no cracks \\
\hline 15 & Al 5083 & 0.929 & 24 & 22 & 23.0 & 19 & 17 & 18.0 & 6.8 & Pass, no cracks \\
\hline 2 & Al 5083 & 1.011 & $\mathrm{X}$ & $\mathrm{X}$ & $\mathrm{X}$ & $\mathrm{X}$ & $\mathrm{X}$ & $\mathrm{X}$ & $\mathrm{X}$ & Pass, cracks \\
\hline 25 & Al 5083 & 1.077 & 33 & 41 & 37.0 & 22 & 22 & 22.0 & 20.8 & Pass, cracks \\
\hline 4 & Al 5083 & 1.086 & $\mathrm{X}$ & $\mathrm{X}$ & $\mathrm{X}$ & $\mathrm{X}$ & $\mathrm{X}$ & $\mathrm{X}$ & $\mathrm{X}$ & Pass, plug forming \\
\hline 3 & Al 5083 & 1.092 & $\mathrm{X}$ & $\mathrm{X}$ & $\mathrm{X}$ & $\mathrm{X}$ & $\mathrm{X}$ & $\mathrm{X}$ & $\mathrm{X}$ & Fail, plug \\
\hline 28 & Al 5083 & 1.114 & 32 & 37 & 34.5 & 21 & 23 & 22.0 & N/A & Fail, complete \\
\hline 1 & Al 5083 & 1.192 & $\mathrm{X}$ & $\mathrm{X}$ & $\mathrm{X}$ & $\mathrm{X}$ & $\mathrm{X}$ & $\mathrm{X}$ & $\mathrm{X}$ & Fail, complete \\
\hline 17 & FSW & 0.869 & 21 & 24 & 22.5 & 17 & 22 & 19.5 & 7.5 & Pass, crack along weld \\
\hline 18 & FSW & 0.922 & 29 & 30 & 29.5 & 22 & 25 & 23.5 & 9.0 & Pass, cracks \\
\hline 19 & FSW & 0.939 & 30 & 39 & 34.5 & 21 & 24 & 22.5 & 9.4 & Pass, cracks \\
\hline 23 & FSW & 0.976 & 38 & 36 & 37.0 & 25 & 26 & 25.5 & 11.9 & Pass, plug forming \\
\hline 27 & FSW & 1.006 & 41 & 39 & 40.0 & 26 & 27 & 26.5 & N/A & Fail, plug \\
\hline 26 & FSW & 1.018 & 36 & 39 & 37.5 & 20 & 27 & 23.5 & N/A & Fail, plug \\
\hline 20 & FSW & 1.034 & 35 & 35 & 35.0 & 28 & 27 & 27.5 & N/A & Fail, plug \\
\hline 22 & FSW & 1.059 & 39 & 35 & 37.0 & 28 & 28 & 28.0 & N/A & Fail, complete \\
\hline 21 & FSW & 1.074 & 41 & 41 & 41.0 & 28 & 28 & 28.0 & N/A & Fail, complete \\
\hline 24 & FSW & 1.077 & 39 & 41 & 40.0 & 25 & 27 & 26.0 & N/A & Fail, complete \\
\hline 12 & GMAW & 0.673 & 12 & 11 & 11.5 & 12 & 11 & 11.5 & 4.0 & Pass, no cracks \\
\hline 11 & GMAW & 0.884 & 24 & 25 & 24.5 & 24 & 23 & 23.5 & 7.5 & Pass, no cracks \\
\hline 13 & GMAW & 0.947 & 32 & 27 & 29.5 & 24 & 24 & 24.0 & 8.8 & Pass, no cracks \\
\hline 14 & GMAW & 0.947 & 34 & 31 & 32.5 & 30 & 24 & 27.0 & 9.0 & Pass, cracks \\
\hline 7 & GMAW & 1.002 & $X$ & $\mathrm{X}$ & $X$ & $\mathrm{X}$ & $\mathrm{X}$ & $X$ & $X$ & Pass, cracks \\
\hline 10 & GMAW & 1.031 & $\mathrm{X}$ & $\mathrm{X}$ & $\mathrm{X}$ & $\mathrm{X}$ & $\mathrm{X}$ & $\mathrm{X}$ & $\mathrm{X}$ & Fail, plug \\
\hline 8 & GMAW & 1.033 & $X$ & $\mathrm{X}$ & $X$ & $\mathrm{X}$ & $\mathrm{X}$ & $X$ & $X$ & Fail, plug \\
\hline 6 & GMAW & 1.056 & $X$ & $\mathrm{X}$ & $X$ & $\mathrm{X}$ & $\mathrm{X}$ & $\mathrm{X}$ & $X$ & Fail, plug \\
\hline 9 & GMAW & 1.097 & $X$ & $\mathrm{X}$ & $X$ & $\mathrm{X}$ & $\mathrm{X}$ & $\mathrm{X}$ & $X$ & Fail, complete \\
\hline 5 & GMAW & 1.164 & $X$ & $\mathrm{X}$ & $X$ & $\mathrm{X}$ & $\mathrm{X}$ & $X$ & $X$ & Fail, complete \\
\hline
\end{tabular}

N/A not applicable, $X$ loss of painted dot pattern from extreme deformation

obtained from DIC analysis of the tensile surface of the FSW, GMAW and Al 5083 bend specimens depicted in Figs. 8 and 9. The similarity in the displacement maps for each material is anticipated as these specimens were loaded to similar machine displacement levels.

GMAW specimens experienced the highest levels of maximum strain, $\varepsilon_{\mathrm{x}}$. The $\varepsilon_{\mathrm{x}}$ strains were measured on the tensile surface along the specimen length. The GMAW specimen showed strain concentration in the weld region, as illustrated in Fig. 10, with a maximum axial strain of $27 \%$. For the FSW material, the $\varepsilon_{\mathrm{x}}$ strains were more evenly distributed across the weld region with a lower maximum value ( $\sim 18 \%)$. The $\mathrm{Al}$ bend specimens showed a similar distribution to the FSW specimens with higher maximum $\varepsilon_{\mathrm{x}}$ strains in the bend region. The maximum measured $\varepsilon_{\mathrm{x}}$ strain for the $\mathrm{Al}$ baseline material was greater
( $\sim 22 \%$ ) than the FSW, and less than the GMAW. Strain maps constructed for the side surface of the bend specimens also showed a wider, less concentrated strain field for the FSW versus GMAW. The $\varepsilon_{\mathrm{y}}$ strain maps in Fig. 10c represent strains in the transverse (across the width) direction on the tensile surface of the specimen. Both weld samples experienced higher compressive strains at the edges than the interior (see Fig. 10c), and a less symmetric distribution of $\varepsilon_{\mathrm{y}}$ strain. The $\varepsilon_{\mathrm{y}}$ strain asymmetry is most evident for the GMAW material and is likely related to weld variability. The compressive $\varepsilon_{\mathrm{y}}$ strain resulted in contraction of the weld region at the specimen edges.

Strain and displacement profiles were also created for each specimen using the ARAMIS DIC software. The profiles for the fusion weld specimen (T14) are shown in Fig. 11, and correspond to the strain and displacement 


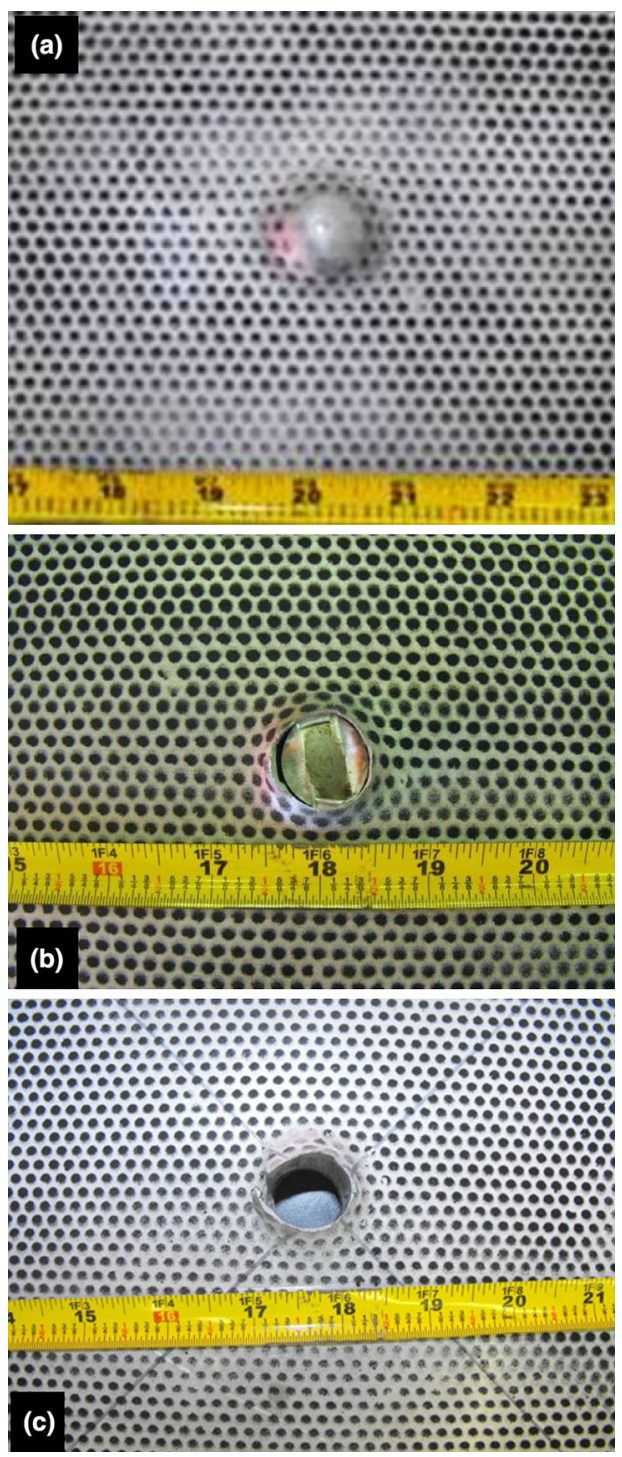

Fig. 14 Failure modes for ballistic experiments a Pass, with cracksductile deformation (Test 2), b Fail with plugging of the projectile in the target (Test 3), c Complete penetration (Test 1). Photos show the back face of $\mathrm{Al} 5083$ targets for projectiles launched at increasing velocities; the scale is in inches

maps in Fig. 10. Each curve in the profile plots represents a progressive time step during specimen loading; the red curve represents the final time step. The $\varepsilon_{\mathrm{x}}$ and displacement profiles are at the centerline (i.e., mid-span) of the tensile surface along the $\mathrm{X}$-direction. The $\varepsilon_{\mathrm{y}}$ profiles are plotted relative to the Y-direction (i.e., specimen width). The profile plots illustrate the progression of strain, and displacement, for each material type. Similar profiles were also obtained for the FSW (T14) and baseline Al (T18) bend specimens corresponding to those shown in Figs. 8, 9, and 10. These are compared with the GMAW profiles in Fig. 12; the plots represent the final time step prior to specimen unloading. The findings are consistent with the strain map observations. The $\varepsilon_{\mathrm{x}}$ profiles show higher maximum strain, and a more concentrated strain region, for the GMAW specimens. The $\varepsilon_{\mathrm{x}}$ strain is lower in the FSW specimen, and distributed over a wider region than for the GMAW and Al 5083 specimens. Figure 12 also compares the magnitude of the compressive strain $\left(\varepsilon_{\mathrm{y}}\right)$ that occurs in the welded specimens versus the $\mathrm{Al}$ base material. The asymmetry of the $\varepsilon_{\mathrm{y}}$ strain profile for the GMAW specimen is evident in comparison to the FSW and baseline $\mathrm{Al}$ materials. The displacements due to loading are similar for each specimen; this was intentional to allow a direct comparison of the three materials.

Additional analyses were performed to further investigate the bending response differences for the three material types. The maximum strain $\left(\varepsilon_{\mathrm{x}}\right)$ on the tensile surface of each bend specimen was determined from DIC analysis, and is listed in Table 1. A parameter, defined as the ratio of the maximum measured strain to machine crosshead displacement (see Table 1) revealed a distinct grouping of the bend test results by material type. The GMAW specimens exhibited the highest strain and ratio of strain versus deflection; the FSW material exhibited the lowest ratio and strain. The ratio for the baseline $\mathrm{Al}$ was between the values for the welds. Plots of longitudinal $\left(\varepsilon_{\mathrm{x}}\right)$ strain versus displacement also reflect the observed differences, as shown in Fig. 13. Two different plots are shown in the figureone with crosshead displacement, the other with specimen displacement. The specimen displacement was determined from the DIC analyses and removes the effects of machine compliance. For a given displacement, the plots indicate that the GMAW specimen endures the highest strain. The FSW specimen, in contrast, exhibits the lowest strains for the same displacement. This is attributed to the higher ductility of the FSW material versus the base material. Differences in the weld microstructures contribute to these results. The fusion welds are weaker than the friction stir welds. The HAZ in the GMAW welds has lower strength and ductility, and leads to larger localized strains. Cracks observed in several of the GMAW bend specimens following testing are indicative of the lower ductility of the GMAW welds. The FSW material is stronger and more ductile than the GMAW (and HAZ) material; the strains can be accommodated over a larger region.

DIC analyses were also performed to evaluate and compare strains on the side surface (through-thickness) of the bend specimens. Strain maps of the side surface also show that the strain field for the FSW material is distributed over a wider region. The peak strains on the side surface of the FSW specimen are lower than for the GMAW and base Al specimens. The strain profile distribution is similar to that observed on the tensile surface. The magnitudes of the longitudinal strains are greatest for the GMAW materials and lowest for the FSW material; the 


\begin{tabular}{|c|c|c|c|c|c|}
\hline Material & $\Delta Z$ Displacement & & $\varepsilon_{\mathbf{x}}$ & $\varepsilon_{y}$ & \\
\hline $\begin{array}{l}\text { Base (T25): } \\
0.98 V_{50}\end{array}$ & $\begin{array}{l}\mathrm{E} \\
\mathrm{E} \\
\text { น }\end{array}$ & $\begin{array}{r}{[\mathrm{mm}]} \\
5.0 \\
4.5\end{array}$ & & & $\begin{array}{r}{[\%]} \\
40 \\
36\end{array}$ \\
\hline $\begin{array}{l}\text { FSW (T23): } \\
0.99 V_{50}\end{array}$ & & $\begin{array}{l}3.0 \\
2.5\end{array}$ & & & $\begin{array}{l}24 \\
20\end{array}$ \\
\hline $\begin{array}{l}\text { GMAW (T14): } \\
0.94 V_{50}\end{array}$ & & 0.5 & & & 8 \\
\hline
\end{tabular}

Fig. 15 DIC analysis results for ballistic experiments shortly after impact (0.04 ms) for: baseline, FSW and GMAW panels. The impact velocities are close to $\mathrm{V}_{50}$ for each material, though the actual

maximum strains for the Al baseline material fall between those for the GMAW and FSW materials.

\section{Ballistic Experiments}

The results of twenty-eight ballistic tests were evaluated for ten welded targets each for the FSW and GMAW materials, and eight Al 5083 targets. Initial experiments were conducted at the velocity extremes with subsequent population of the mid-range velocities. The numerical simulation results were used for initial velocity selection for the Al 5083 baseline material. A modified $\mathrm{V}_{50}$ was determined from the ballistic tests of Al 5083; this guided velocity selection for the welded panels. The term "modified $\mathrm{V}_{50}$ is used since fewer tests were conducted than are generally used for determination of $V_{50}$. Hence, the $V_{50}$ obtained may differ from a $\mathrm{V}_{50}$ obtained with a larger data set. Higher values of $\mathrm{V}_{50}$ were measured for the monolithic targets versus the welded targets; $V_{50}$ 's were similar for both weld types.

The test results are summarized in Table 2, and include normalized velocities as well as strains and deflections measured with DIC analyses (discussed below). A pass/fail classification is listed in the final column of the table. Failure is further categorized based on plugging of the projectile in the target versus complete penetration of the target with ejection of the projectile and a target plug. At the lower velocities, damage initiated with cracking around the impact location. Plugging of the projectiles occurred as the impact velocity increased. At higher velocities, a plug velocities differ. The $\mathrm{Z}$ displacement maps show the extent of deformation. Strain maps are shown on the right for $\varepsilon_{\mathrm{x}}$ and $\varepsilon_{\mathrm{y}}$

of the aluminum or weld material was ejected ahead of the projectile. Complete penetration occurred at the highest velocities. The deformation process appeared similar for the three different material types (baseline, FSW, GMAW). Ductile deformation of the targets was observed. The deformation zone was concentrated at the impact location with minimal effect on the surrounding regions of the impacted plate. This zone was characterized by extensive bulging at the impact location prior to target failure. Three stages of deformation were observed and are illustrated in Fig. 14 for the Al 5083 baseline material: (a) ductile deformation, (b) plugging, and (c) complete penetration of the target.

Extensive DIC analysis was also performed for the ballistic experiments. Peak strains, and strain and deflection (in the thickness direction) at the impact point, were determined for the velocity range evaluated; see Table 2. For some targets, strain and deflection were not readily obtained from the DIC measurements due to patterning inconsistencies or pattern loss resulting from the extensive deformation that occurred during impact. The affected targets are indicated by the X's in the table. Customized decals were implemented later in the test program, as discussed in the "Experimental Procedure" section and illustrated in Fig. 5, to overcome loss of the paint patterns. N/A in the Z-deflection column in Table 2 indicates "not applicable"; this applies when the targets were completely penetrated by the projectile.

Strain and deflection maps were also obtained from DIC analyses of the back surface of the ballistic targets for 


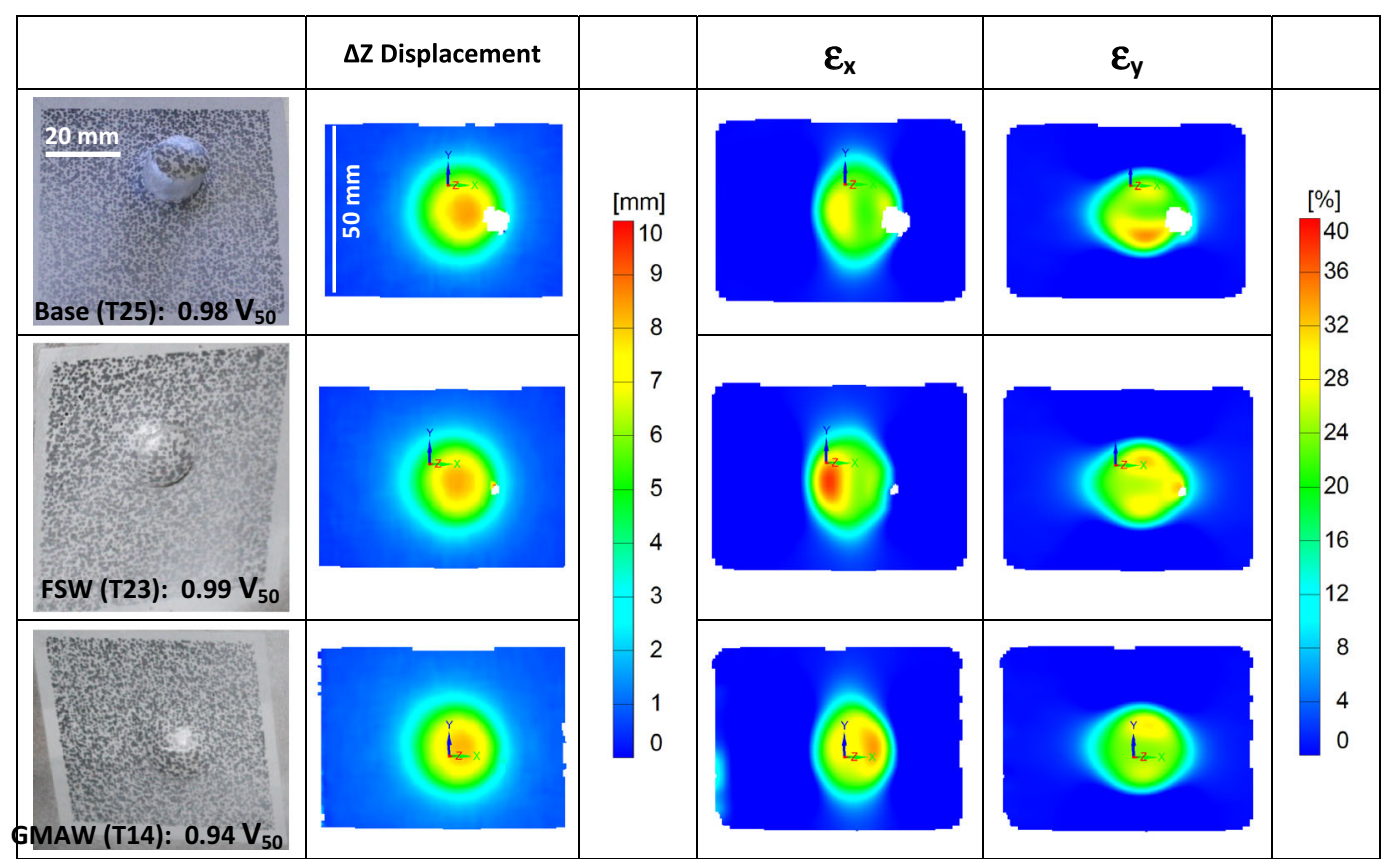

Fig. 16 DIC analysis results for ballistic experiments at times just prior to cracking for: baseline, FSW and GMAW panels. The impact velocities are close to $\mathrm{V}_{50}$ for each material, though the actual

velocities differ. The $\mathrm{Z}$ displacement maps show the extent of deformation. Strain maps are shown on the right for $\varepsilon_{\mathrm{x}}$ and $\varepsilon_{\mathrm{y}}$

(b)

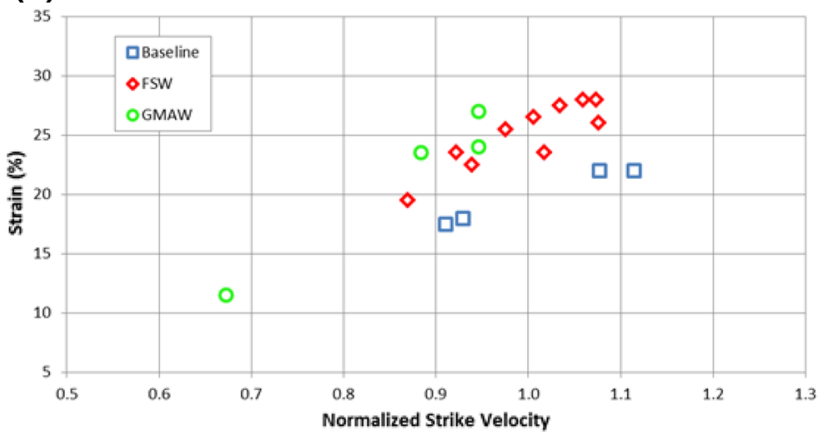

(d)

Plug Velocity (Fails Only)

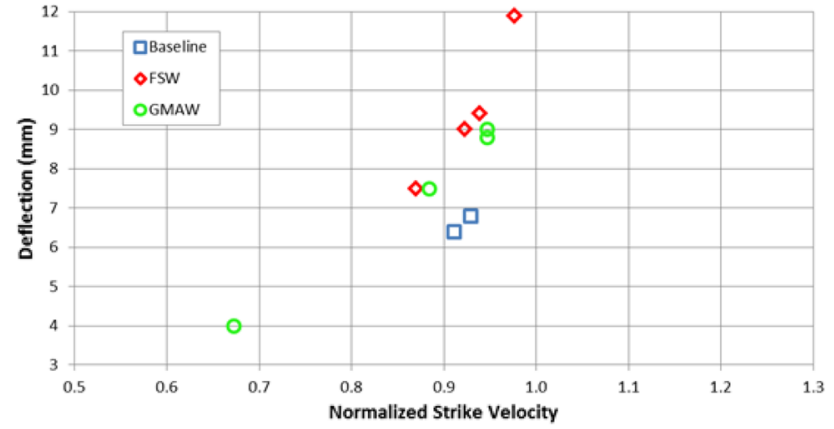

Fig. 17 Measurements obtained from DIC analyses and plotted versus normalized strike velocity for baseline Al, FSW and GMAW materials. a Peak strain values, b strain at the impact point,

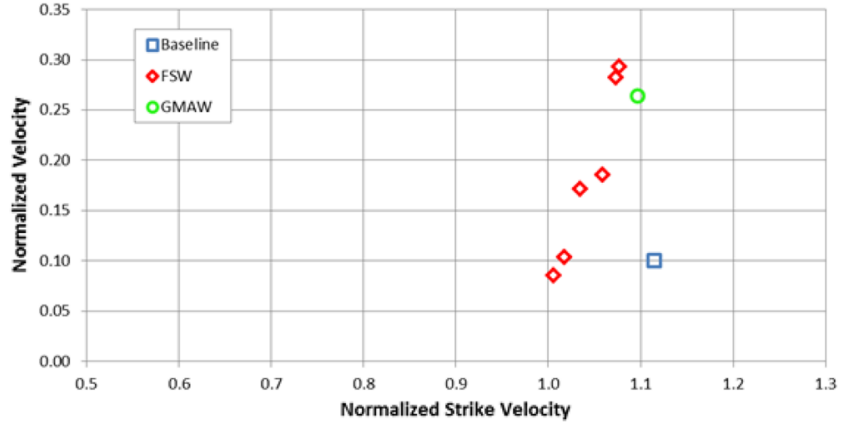

c deflection at the impact point (passes only) and d plug velocity (fails only). Fewer data points are shown for the GMAW and baseline materials owing to patterning limitations 

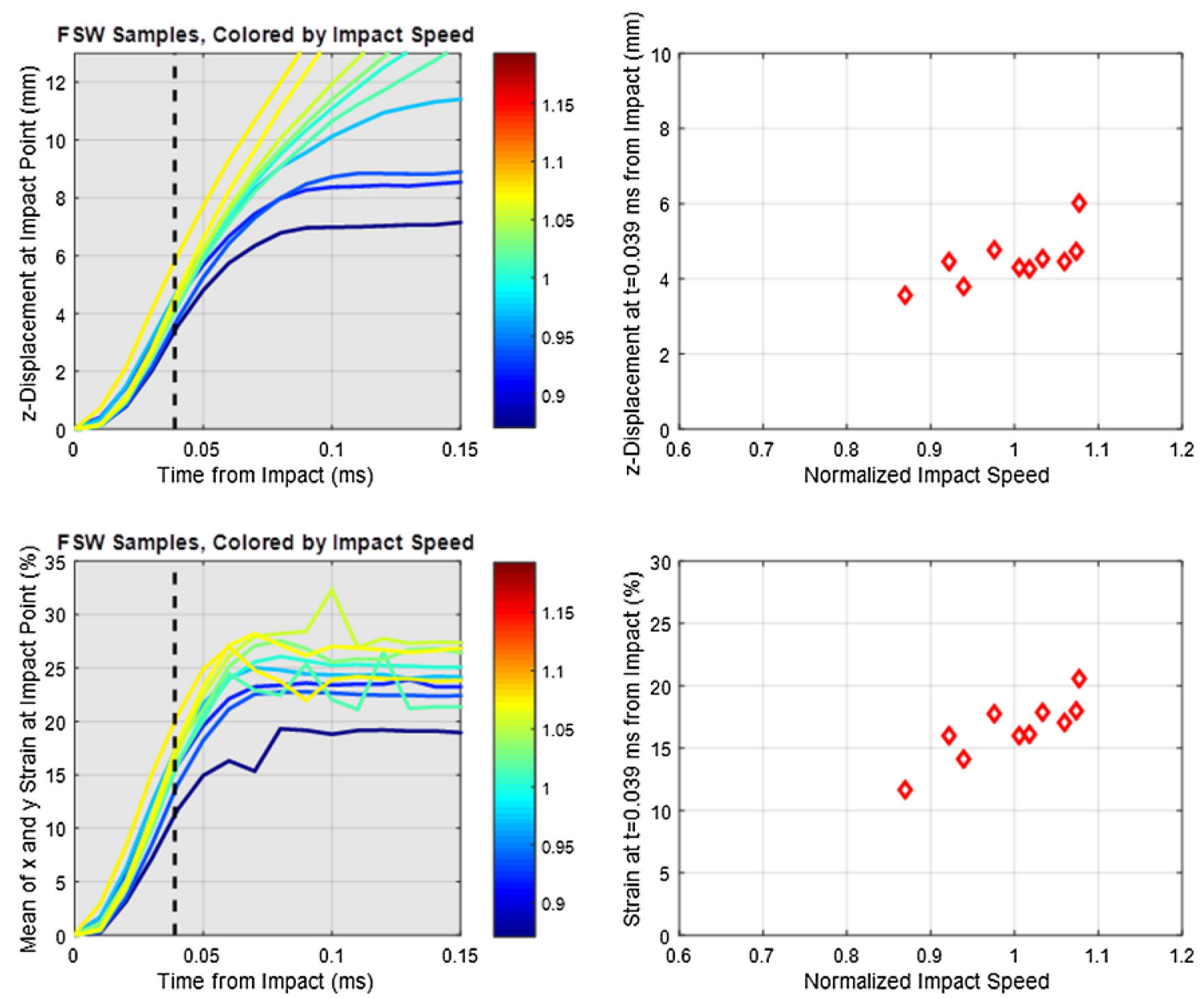

Fig. 18 DIC results for the FSW samples were reduced to obtain time histories for $\mathrm{Z}$ displacement and mean strain at the impact location. The color coding represents impact speed differences (red

highest). The results are for FSW targets at $0.039 \mathrm{~ms}$ after impact, and are used to populate the plots on the right

different times during projectile impact. The DIC results were used to better understand the damage response differences. The analyses emphasized the deformed target region surrounding the impact location as damage was concentrated in this region only. Immediately after impact $(0.04 \mathrm{~ms})$, the DIC results indicate the FSW and Al 5083 targets experienced more back face deflection than the GMAW target. This is evident in the strain maps, shown in Fig. 15, for early times. The FSW target achieved the highest strains $(\sim 20 \%)$ with the baseline Al showing a similar strain profile and slightly lower strain magnitudes $(\sim 16 \%)$. The GMAW material exhibited lower $(<12 \%)$ strains immediately following impact. These early-time differences are attributed to the lower ductility of the GMAW material that limits the extent of deformation versus the more ductile FSW material (and $\mathrm{Al} 5083$ base alloy). The strain values for all materials increased with time after impact. The conditions just prior to cracking are shown in the strain maps in Fig. 16. For the FSW material, maximum strains in the X-direction approached $40 \%$. Peak strains in the GMAW material were slightly less $(\sim 35 \%)$ with the base $\mathrm{Al}$ exhibiting the lowest strain values $(28-30 \%)$. The white regions in the strain maps for the $\mathrm{Al}$ material in Fig. 16 are regions where the dot pattern was not conducive for analysis.

Data from the DIC analyses were further analyzed to provide comparisons for the range of strike velocities. Peak strain values and strain at the impact point are compared in the plots in Fig. 17, and are also listed in (b) Table 2. The peak strain is the average of the $\mathrm{x}$-strain along the $\mathrm{x}$-axis and the $y$-strain along the $y$-axis. Peak strains exceeding $40 \%$ were determined for the FSW material. It is possible that similar peak strains occurred in the GMAW material as well, though pattern loss for the GMAW and Al baseline targets tested early in the program limited the extent of peak strain data that could be obtained. The general data trend in Fig. 17 shows higher peak strains for the FSW material (versus GMAW and $\mathrm{Al}$ baseline). This can be 

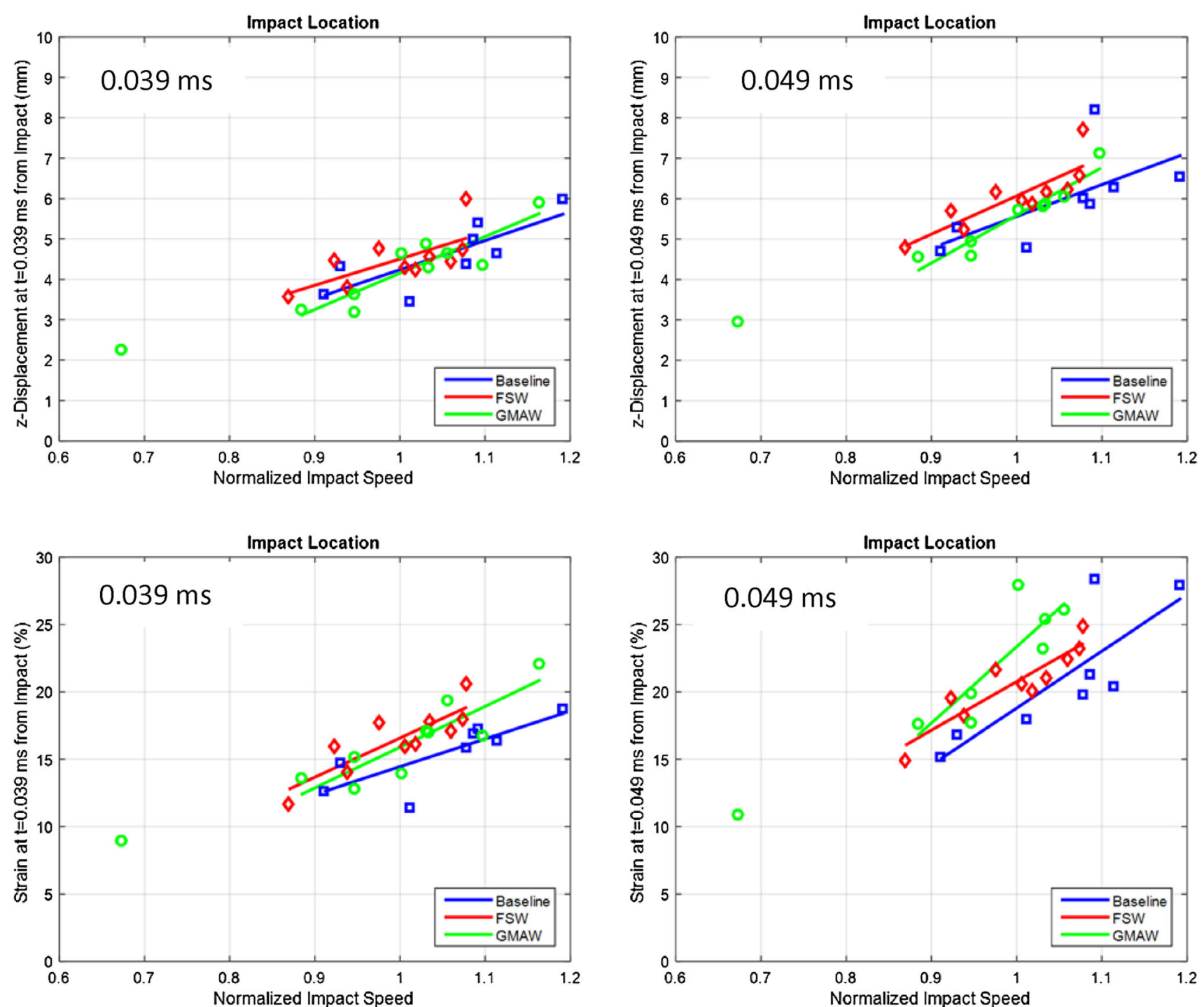

Fig. 19 Comparison of deflection (top) and mean strain (bottom) for baseline Al, FSW, and GMAW targets at $0.039 \mathrm{~ms}$ and $0.049 \mathrm{~ms}$ after impact. The plots were created from analysis of the time history data, as shown in Fig. 18 for the FSW material

related to the higher ductility of the FSW material versus GMAW and Al 5083 baseline. The GMAW material shows higher strains at the impact point than the FSW or baseline materials, and is attributed to more cracking observed at the impact location. Deflection at the impact point, plotted in Fig. 17c, shows similar trends for both weld materials. Both weld types exhibited more deflection at the impact point than the base material. The measurements for velocity of the ejected plug show a monotonic increase with strike velocity for the FSW material.

Subsequent analyses were also performed to obtain plots of displacement and mean strain at the impact location as a function of impact velocity and time after impact. The data in Fig. 18 for the FSW material are representative of the analysis procedure. The curves on the left show the progression in displacement and mean strain versus time; the curves are color-coded based on impact velocity. The results for each material were compared at two different times after impact: $0.039 \mathrm{~ms}$ and $0.049 \mathrm{~ms}$. The data obtained at these times, from the curves on the left in Fig. 18, were then used to populate the plots on the right. The displacement and strain data for each material type were cross-plotted for direct comparison, as shown in Fig. 19. Comparison of the displacement versus impact velocity plots at two different times after impact shows minimal differences at $0.039 \mathrm{~ms}$ after impact and more displacement for the FSW material (versus GMAW and $\mathrm{Al}$ ) at $0.049 \mathrm{~ms}$ after impact. This is consistent with the deflection and strain maps in Fig. 15 at $0.049 \mathrm{~ms}$ after impact. The GMAW material exhibits a steeper slope on the deflection plot than the other materials with increasing velocity. The mean strain comparison plots in Fig. 19 show 
a more distinct grouping of the materials at $0.049 \mathrm{~ms}$ after impact. For a specific impact velocity, the GMAW material exhibits higher mean strains than the FSW and Al 5083 materials. The materials ranking and behavior for the ballistic targets is similar to that observed for the three point bend tests. Metallurgical analysis of the ejected target plugs revealed greater damage to the GMAW material versus the FSW and Al baseline. Evidence of spall was observed on the back of the target at velocities great than $V_{50}$.

\section{Conclusions}

Digital image correlation (DIC) analyses provided beneficial comparisons of the deformation response of fusion versus friction stir welds at high and low strain rates. For the low strain rate $\left(1 \mathrm{~s}^{-1}\right)$ bend tests, a parametric comparison of the maximum measured strain to displacement ratio revealed a distinct grouping of the three material types. The FSW material had the lowest strain:displacement ratio. The GMAW material exhibited the highest value of this parameter, indicative of higher strains for the same displacement levels.

A similar ranking of the materials was also observed for the ballistic experiments. The deformation process during ballistic impact appeared similar for the three materials. Ductile deformation occurred at the impact location with projectile plugging and ejection of the plug and projectile at higher velocities. Extensive DIC analysis of the ballistic experiments showed a steeper slope for the GMAW material (versus FSW and $\mathrm{Al}$ ) when comparing target strain and displacement shortly after impact, and over a range of velocities. The experimental results, DIC analyses and metallurgical evaluation results indicate more extensive damage occurs in the GMAW material than for the FSW or Al baseline materials.

Acknowledgments The authors gratefully acknowledge the support of the US Army TARDEC for this work. Technical insights and beneficial discussions with Mr. Bryan Pruess and Mr. Gary Tatro of TARDEC are greatly appreciated. Mr. Paul Chenier (Onodi Tool and Engineering) is acknowledged for his technical and administrative support, as well as assistance in fabricating and obtaining welded panels for the test program. The contributions of Martin McDonnell and Matt Rogers (TARDEC) and numerous SwRI colleagues are also gratefully acknowledged.

\section{References}

1. Nickodemus GH, Kramer LS, Pickens JR, Burkins MS (2002) Aluminum advances for ground vehicles. Adv Mater Process 160(2):51-55
2. Chapter 4, Lightweighting land-based vehicles in application of lightweighting technology to military vehicles, vessels and aircraft, The National Academies Press, Washington, DC, pp 85-102, 2012

3. Alcoa News Release (2013) Latest alcoa armor now specified by U.S. Army Research Lab for highest strength, troop protection in military vehicles. http://www.alcoa.com/global/en/news/news_ detail.asp?pageID $=20131010005956$ en \&news Year $=201$. Accessed 20 Oct 2013

4. Thryft AR (2013) Aluminum armor plate good enough for Humvees, Materials and Assembly

5. Doherty K, Squillacioti R, Cheeseman B, Placzankis B, Gallardy D (2012) Expanding the availability of lightweight aluminum alloy armor plate procured from detailed military specifications. In: Weiland H, Rollett AD, Cassada WA (eds) 13th international conference on aluminum alloys (ICAA13), Wiley, Hoboken, 2012

6. Armor Plate, Aluminum Alloy, Weldable 5083, 5456 and 5059, MIL-DTL-46027K, July 2007

7. Clausen AH, Borvik T, Hopperstad OS, Benallal A (2004) Flow and fracture characteristics of aluminium alloy AA5083-H116 as a function of strain rate, temperature and triaxiality. Mater Sci Eng A 364:260-272

8. Nandan R, DebRoy T, Bhadeshia HKDH (2008) Recent advances in friction-stir welding-process, weldment structure and properties. Prog Mater Sci 53(6):980-1023

9. Colligan KJ, Konkol PJ, Fisher JJ, Pickens JR (2003) Friction stir welding demonstrated for combat vehicle construction. Weld $\mathbf{J}$ 82(3):34-40

10. Colligan KJ, Fisher JJ, Gover EJ, Pickens JR (2002) Friction stir welding in the advanced amphibious assault vehicle. Adv Mater Process 160(9):39-41

11. Campbell G, Stotler T (1999) Friction stir welding of armor grade aluminum plate. Weld J 78(12):45-47

12. Grujicic M, Arakere G, Yalavarthy HV, He T, Yen C-F, Cheeseman BA (2011) Development of a robust and cost-effective friction stir welding process for use in advanced military vehicles. J Mat Eng Perform 20(1):11-23

13. Grujicic M, Arakere G, Hariharan A, Panduranagan B (2012) A concurrent product-development approach for friction-stir welded vehicle-underbody structures. J Mat Eng Perform 21(4):437-449

14. Thomas WM, Nicholas ED, Needham JC, Murch MG, TempleSmith P, Dawes CJ (1991) Friction stir butt welding, GB Patent No. 9125978.8, International Patent Application No. PCT/GB92/ 02203, 1991

15. Threadgill PL, Leonard AJ, Shercliff HR, Withers PJ (2009) Friction stir welding of aluminium alloys. Int Mater Rev 54(2):49-93

16. Mishra RS, Ma ZY (2005) Friction stir welding and processing. Mater Sci Eng 50(1-2):1-78

17. Mishra RS, Mahoney MW (2007) ASM International specialty handbook: friction stir welding and processing. ASM International, Metals Park

18. The Welding Institute (TWI) (2016) 11th international friction stir welding symposium, The Welding Institute (TWI), Cambridge

19. Murr LE (2010) A review of FSW research on dissimilar metal and alloy systems. J Mat Eng Perform 19(8):1071-1089

20. Meshram SD, Mohandas T, Reddy GM (2007) Friction welding of dissimilar pure metals. J Mat Proc Technol 184(1):330-337

21. Svensson LE, Karlsson L, Larsson H, Karlsson B, Fazzini M, Karlsson J (2000) Microstructure and mechanical properties of friction stir welded aluminum alloys with special reference to AA 5083 and AA6082. Sci Technol Weld Join 5(5):285-296. doi:10. $1179 / 136217100101538335$ 
22. Fonda RW, Bingert JF (2004) Microstructural evolution in the heat-affected zone of a friction stir weld. Metall Mater Trans A 35A:1487-1499

23. Mahoney MW, Rhodes CO, Flintoff JO, Spurling RA, Bingel WH (1998) Properties of friction-stir-welded 7075 T651 aluminum. Metall Mater Trans A 293:1955-1964

24. Sano T, Yu J, Medintz J, Yen C-F, Doherty K (2012) The effect of friction stir welding on the microstructure and tensile properties of Al 2139-T8 alloys. In: Suarez CE (ed) Light Metals 2012. TMS (The Minerals, Metals \& Materials Society), Warrendale, pp 497-501

25. Dannemann KA, Chocron S, Anderson Jr. CE (2010) Comparison of mechanical and constitutive response for five aluminum alloys for armor applications Presented at 16th US National Congress on Theoretical and Applied Mechanics, State College, Pennsylvania, June 2010

26. Dannemann KA, Carpenter AJ, Scott NL, Chocron S (2014) A comparison of the mechanical response of weld regions in friction stir welded aluminum alloy 7085. Presented at Materials Science \& Technology 2014, Pittsburgh, Oct 2014

27. Chao YJ, Wang Y, Miller KW (2001) Effect of friction stir welding on dynamic properties of AA2024-T3 and AA7075T7351, Weld J Res Suppl 80(8):196-200

28. Gunnarsson CA, Weerasooriya T, Love B (2012) Mechanical response of friction stir welded aluminum 2139-T8 as a function of loading rate and stress-state. In: Chalivendra V, Song B, Casem D (eds) Dynamic behavior of materials. Proceedings of 2012 annual conference on experimental and applied mechanics, vol 1. Springer, New York, pp 67-71

29. Dannemann KA, Chocron S, Nicholls AE (2010) Evaluation of welded tensile specimens in the Hopkinson bar. Presented at Society for experimental mechanics annual conference, Indianapolis, June 2010

30. Dannemann KA, Bigger RP, Chocron S, Nahshon K (2011) Dynamic strain measurement of welded tensile specimens using digital image correlation. Presented at Society for Experimental Mechanics Annual Conference, Uncasville, June 2011

31. Baig M, Khan AS, Choi S-H, Lee E, Grujicic M, Arakere G, Yalavarthy HV, He T, Yen C-F, Cheeseman BA (2015) Effect of manufacturing processes and welding type on quasi-static and dynamic responses of aluminum alloys: experiments and modeling. J Dyn Behav Mater 1:299-314

32. Lannom M, Helmick B, Garriot F, Farrington J (2013) Ballistics testing of friction stir welded 2050-T8 aluminum lithium, American Welding Society Poster Competition, Orange Coast College

33. Sullivan A, Derry C, Robson JD, Horsfall I, Prangnell PB (2011) Microstructure simulation and ballistic behavior of weld zones in friction stir welds in high strength aluminum $7 \mathrm{xxx}$ plate. Mater Sci Eng A 528(9):3409-3422

34. Johnson T, Hunz B, West M, Jasthi B, Ellingsen M, Widener C, Muci K (2011) Evaluation of the response of friction stir processed panels under ballistic loading. Presented at 26th International symposium on ballistics, DEStech Publications, Inc., Miami

35. Johnson T, Curtis T, Jasthi B, East E, Widener C, West M (2013) Effect of friction stir processing on armor grade materials. In: Mishra R, Mahoney MW, Sato Y, Hovonski Y, Verma R (eds) Friction stir welding and processing VII. TMS (The Minerals, Metals \& Materials Society), Warrendale

36. ASTM B209, Standard specification for aluminum and aluminum-alloy sheet and plate, book of standards Volume 02.02, ASTM International, West Conshohocken

37. AWS D17.3/D17.3M: 2010, Specification for Friction Stir Welding of Aluminum Alloys for Aerospace Applications, D17 Committee on Welding in the Aircraft and Aerospace Industry, 1st edition, 1 July 2009

38. Johnson GR, Cook WH (1983) A constitutive model and data for metals subjected to large strains, high strain rates and high temperatures, In: Proceedings of the seventh international symposium on ballistics, The Hague 